Annales Geophysicae (2003) 21: 693-708 (C) European Geosciences Union 2003

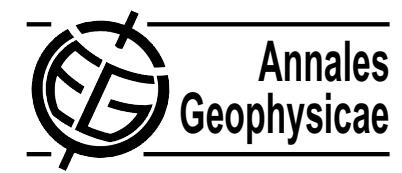

\title{
Multi-instrument study of the dynamic cusp during dominant IMF $B_{y}$ conditions
}

\author{
H. Khan ${ }^{1}$, M. Lester ${ }^{2}$, J. A. Davies ${ }^{2}$, S. E. Milan ${ }^{2}$, and P. E. Sandholt ${ }^{3}$ \\ ${ }^{1}$ NASA Goddard Space Flight Center, Interplanetary Physics Branch, Greenbelt, MD 20771, USA \\ ${ }^{2}$ University of Leicester, Leicester, LE1 7RH, UK \\ ${ }^{3}$ University of Oslo, Oslo, Norway
}

Received: 22 October 2001 - Revised: 12 September 2002 - Accepted: 18 September 2002

\begin{abstract}
We present multi-instrument observations using the meridian scanning photometer (MSP) at Ny Ålesund, the EISCAT Svalbard radar (ESR) and the CUTLASS Finland HF radar, to investigate the dynamics of the cusp region during pulsed reconnection events. The optical data obtained from the MSP indicate the presence of several polewardmoving auroral forms (PMAFs) which have been previously identified as the auroral signature of pulsed reconnection. Furthermore, the optical green line $(557.7 \mathrm{~nm})$ luminosity indicates a loss of emission equatorward of the location of the onset of the PMAFs, characteristic of magnetospheric plasma escaping to the magnetosheath along newly opened field lines. This reduction in green line luminosity creates a "dark region", the equatorward edge of which is found to lie close to the boundary between high and low spectral widths observed by the CUTLASS Finland radar. High spectral widths on the dayside have previously been identified as a good indicator of cusp backscatter. Both of these boundaries have been suggested to provide an accurate representation of the location of the open/closed field line boundary. The ESR observations show enhancements in electron density and electron temperature occurring in conjunction with the optical PMAFs. The observations demonstrate some correspondence with the theoretical predictions of Davis and Lockwood (1996), who used an auroral precipitation model to predict ESR observations in the vicinity of the cusp. However, the limitations of this model are apparent under conditions of large plasma flows in the ionosphere. Finally, convection velocities obtained from the HF radar data illustrate a flow regime similar to that predicted to be driven by strong IMF $B_{y}$, as described by Cowley and Lockwood (1992), demonstrating an initial azimuthal flow followed by a rotation to more poleward directions.
\end{abstract}

Key words. Ionosphere (ionosphere-magnetosphere interactions; particle precipitation) - Magnetospheric physics

Correspondence to: H. Khan

(hkhan@lepvax.gsfc.nasa.gov) (magnetopause, cusp and boundary layers)

\section{Introduction}

Reconnection at the dayside magnetopause boundary, as envisaged by Dungey (1961), has proven to explain successfully many aspects of the transport of mass, momentum and energy from the solar wind into the near-Earth magnetospheric region. The principal controller of dayside reconnection has been identified by polar-orbiting satellites as the orientation and magnitude of the interplanetary magnetic field (IMF) (e.g. Heppner, 1972; Reiff et al., 1981; Reiff and Burch, 1985). Such dayside reconnection results in the excitation of large-scale convection-driven flow patterns (e.g. Cowley, 1981; Lockwood et al., 1993a; Weimer, 1995; Khan and Cowley, 1999; Ruohoniemi and Baker, 1998), together with the precipitation of magnetosheath particles into the magnetosphere and ionosphere via the magnetospheric cusp region, producing a characteristic signature in both satellite (e.g. Newell and Meng, 1992, 1994) and ground-based instrumentation (e.g. Pinnock et al., 1995; Sandholt et al., 1990, 1998; Milan et al., 1999, 2000). Spacecraft observations made in the vicinity of the magnetopause boundary have shown that transient reconnection bursts, known as "flux transfer events" (FTEs), identified by a characteristic bi-polar signature in the magnetopause normal component, occur on a regular basis (Russell and Elphic, 1978, 1979; Haerendel et al., 1978). Such transient reconnection may be expected to result in an ionospheric signature which is itself pulsed. There is, however, still considerable controversy over whether reconnection is indeed a pulsed phenomenon (e.g. Lockwood et al., 1994) or whether it remains largely continuous (e.g. Newell and Sibeck, 1993). Nevertheless, there exists a vast amount of evidence for pulsed and quasi-periodic reconnection, including pulsed auroral signatures of the cusp seen with optical instruments, such as meridian scanning photometers (MSP) (e.g. Sandholt et al., 1990, 1998) and bursty ionospheric convection observed 
using remote-sensing techniques, such as incoherent scatter radars (e.g. van Eyken, 1984; Lockwood et al., 1989, 1993b) and coherent scatter radars (Goertz et al., 1985; Baker et al., 1995; Provan et al., 1998; Pinnock et al., 1995). In addition, several studies have combined data from a number of these ground-based techniques to provide a greater insight into the spatial and temporal evolution of the transient magnetospheric processes at the magnetopause and the subsequent excitation of plasma and particle events in the ionosphere (Moen et al., 1995; Yeoman et al., 1997; Milan et al., 2000; Lockwood et al., 2000; Davies et al., 2002).

There have, however, been only a handful of studies in which satellites have been in favourable positions close to the magnetopause boundary so as to observe FTEs in-situ in conjunction with simultaneous observations of the ionospheric response by means of optical or radar techniques (Elphic et al., 1990; Neudegg et al., 1999, 2000). With the successful launch of the Cluster spacecraft, Wild et al. (2001) recently presented multi-point magnetic field measurements made while the spacecraft traversed the magnetopause boundary on an outbound pass, together with conjugate ground-based radar observations. Their case study clearly showed FTE signatures at the magnetopause boundary with corresponding transient signatures observed by the CUTLASS radar, termed poleward-moving radar auroral forms (PMRAFs) or pulsed ionospheric flows (PIFs), and also evidence in the EISCAT Svalbard Radar (ESR) of increased cusp precipitation associated with reconnection pulses.

The ESR is ideally located to observe the effects in the ionospheric plasma of the particle precipitation associated with transient reconnection processes. Also, it is situated close to optical instrumentation which can be used to observe the intensity increases at different wavelength bands caused by this precipitation into the ionosphere. Davis and Lockwood (1996) have modelled the response in ESR observations of pulsed reconnection processes depending on the location of the radar relative to the cusp boundary. They predict that enhancements in electron density and temperature in response to precipitation are markedly different for the different positions of the ESR relative to the cusp boundary and thus, provided a framework to place ESR observations in spatial context with the magnetospheric dynamics. Lockwood et al. (2000) have presented ESR observations of the predicted enhancements in electron density and temperature in conjunction with optical signatures of pulsed reconnection, which they compared to the simulations.

In the present study, we have used several of the groundbased techniques mentioned above to identify the ionospheric footprint of the cusp, and we attempt to relate luminosity increases observed by the MSP to signatures observed by the ESR and CUTLASS radars. The data are interpreted with reference to pulsed reconnection models of excitation of flow in the high-latitude ionosphere (e.g. Cowley et al., 1991; Cowley and Lockwood, 1992) and the ESR observations are compared with the predictions made Davis and Lockwood (1996).

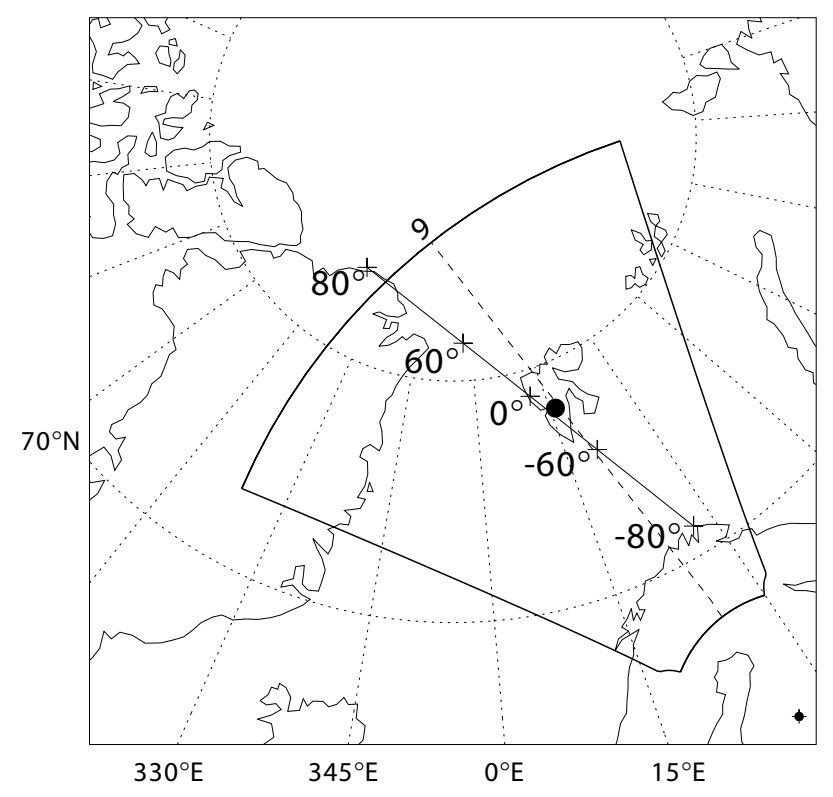

Fig. 1. Geographic map showing the location of the ESR (black circle), the meridian scan path of the MSP located at Ny Ålesund projected to an altitude of $250 \mathrm{~km}$ (solid black line) and the CUTLASS Finland radar f-o-v (grey shaded area). The dotted line represents the path of beam 9 of the Finland radar which passes over the ESR.

\section{Instrumentation}

The ESR is located close to Longyearbyen at a geographic position of $78.20^{\circ} \mathrm{N}, 15.82^{\circ} \mathrm{E}$ and comprises of two antennas, a fixed 42-m dish pointing field-aligned and a fully steerable 32-m dish (Wannberg et al., 1997). For the interval discussed here, the 32-m steerable dish was operated in a fieldaligned mode (geographic azimuth $180.6^{\circ}$, elevation $81.6^{\circ}$ ). The GUP3 modulation scheme was transmitted, which combines both plain (long pulse) and phase-coded (alternating code) pulses to observe over a continuous range of altitudes from 90 to $1000 \mathrm{~km}$. A moving target clutter cancellation technique was employed to remove those echoes arising from the surrounding mountains up to a range of $150 \mathrm{~km}$, so that only ionospheric signals remain.

The Cooperative UK Twin Located Auroral Sounding System (CUTLASS) forms the eastern-most pair of the international Super Dual Auroral Radar Network (SuperDARN) (Greenwald et al., 1995). Only data from the CUTLASS Finland radar (Milan et al., 1997), located at Hankasalmi $\left(62.3^{\circ} \mathrm{N}, 26.6^{\circ} \mathrm{E}\right)$, were used for this study. The radar, which is frequency agile within the range $8-20 \mathrm{MHz}$, detects ionospheric backscatter from field-aligned irregularities. At F-region altitudes these irregularities move with the background plasma (e.g. Davies et al., 1999b, 2000 and references therein), thus providing a tracer for plasma flow in the ionosphere. During standard operations, the radar performs a full scan of 16 beam positions (from beam 15 in the east to beam 0 in the west), with each beam separated by $3.24^{\circ}$ in azimuth, and a dwell time for each beam of $3 \mathrm{~s}$ or $7 \mathrm{~s}$. Each 
beam is gated into 75 range gates of $45 \mathrm{~km}$ in length along the line-of-sight (1-o-s) of the radar. This configuration provides coverage of $52^{\circ}$ in azimuth and over $3000 \mathrm{~km}$ in range (an area of over $4 \times 10^{6} \mathrm{~km}^{2}$ ) every 1 or $2 \mathrm{~min}$. For the interval presented here, the CUTLASS Finland radar was operating in a high-time resolution mode, where the dwell time for each beam was reduced to $2 \mathrm{~s}$, enhancing the temporal resolution of the full 16 beam scan to $32 \mathrm{~s}$. The lag to the first range gate was extended from $180 \mathrm{~km}$ (standard mode) to $630 \mathrm{~km}$ with range gates reduced to $30 \mathrm{~km}$ in length. This provided higher spatial resolution in latitude over the auroral zone and the ESR field-of-view (f-o-v). For each of the beams and ranges an 18-lag complex autocorrelation function is determined, from which the line-of-sight Doppler velocity, spectral width, and backscatter power of the irregularities are derived. Figure 1 shows a schematic of the CUTLASS Finland field-of-view, together with the location of the other ground instrumentation used in this study.

Finally, the meridian-scanning photometer (MSP) located at Ny Ålesund, Svalbard (geographic position of $78.9^{\circ} \mathrm{N}$, $11.9^{\circ} \mathrm{E}$ ) was used to provide intensities of $630.0 \mathrm{~nm}$ (red) and $557.7 \mathrm{~nm}$ (green) wavelength auroral emissions integrated along the beam, corresponding to transitions of excited atomic oxygen. The red line auroral emissions can occur anywhere between $200 \mathrm{~km}$ and $550 \mathrm{~km}$ (F-region), with the peak emission corresponding to luminosity excited by precipitating electrons of energies of the order of $100 \mathrm{eV}$, typically occurring at $250 \mathrm{~km}$. The green line emissions may occur between 110 and $150 \mathrm{~km}$ (E-region), corresponding to luminosity excited by precipitated keV electrons. For the purposes of this study, an emission altitude of $250 \mathrm{~km}$ is assumed for the red line intensities, while a lower emission altitude of $150 \mathrm{~km}$ is assumed for the green line intensities. This latter altitude is higher than the $110 \mathrm{~km}$ normally assumed and a discussion of this choice is provided later. The MSP scans approximately along the magnetic meridian from elevations of $+80^{\circ}$ (northwards) to $-80^{\circ}$ (southwards) with a scan period of $18 \mathrm{~s}$; the southern portion of the scan path approximately follows beam 9 of the CUTLASS Finland radar (see Fig. 1).

\section{Observations}

In this study, we concentrate on data from 06:45-07:20 UT on 4 December 1999, when the ESR radar was observing plasma enhancements reminiscent of cusp processes in the ionosphere. During this time, the CUTLASS Finland radar was observing in the pre-noon sector with the ESR and MSP located roughly in the centre of its f-o-v (Fig. 1). Solar wind and interplanetary field conditions were monitored using the ACE spacecraft and provide the information about the magnetospheric configuration during the ionospheric features presented.

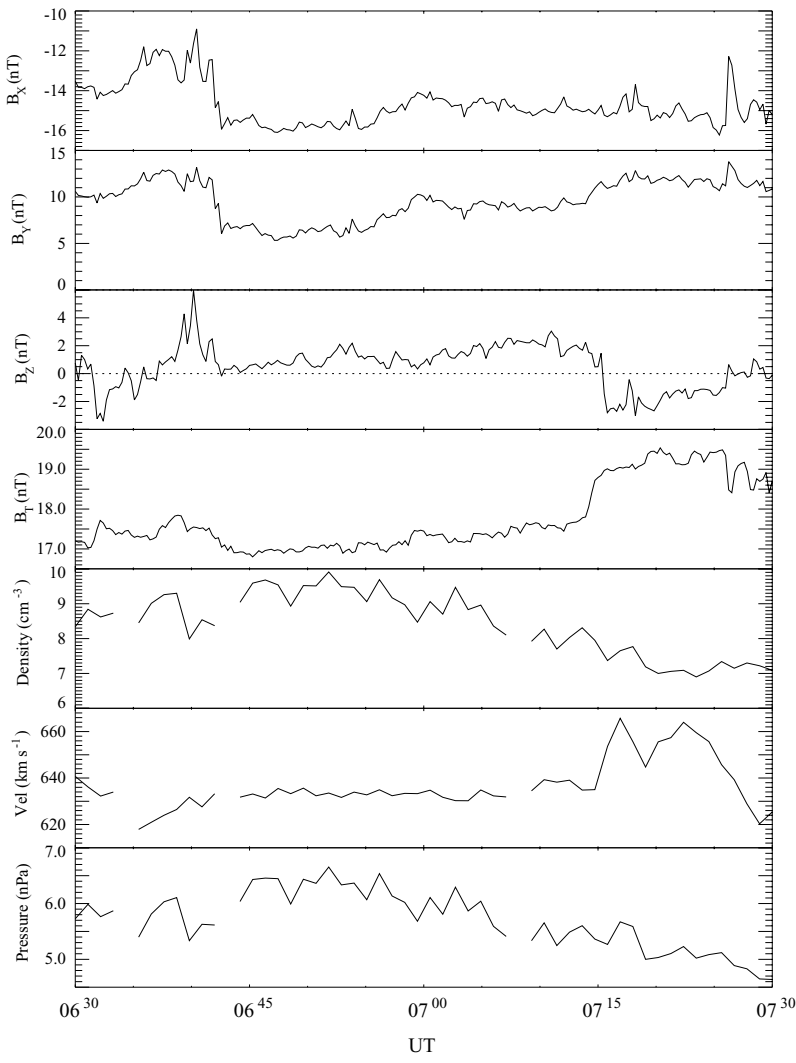

Fig. 2. Solar wind and IMF data obtained by the ACE spacecraft for the interval 06:30-07:30 UT, but where the data have been shifted in time by $42 \mathrm{~min}$ to account for the solar wind propagation delay from the spacecraft to the subsolar magnetopause. From top to bottom, the panels of the figure show the three GSM components of the IMF, together with the field strength, and the density, velocity, and dynamic pressure of the solar wind.

\subsection{Solar wind conditions}

Conditions in the upstream solar wind and IMF were measured using the SWEPAM and MAG instruments on the ACE spacecraft (McComas et al., 1998; Smith et al., 1998; Stone et al., 1998). ACE was located in the solar wind near the Earth-Sun L1 libration point, and for the purposes of this study, magnetic field and plasma data at $16 \mathrm{~s}$ and $64 \mathrm{~s}$ resolution, respectively, are used. All magnetic field and spacecraft position data presented in this paper are in GSM coordinates. At the time of these observations, ACE was located at GSM coordinates $(X, Y, Z) \approx(+220,+20,-25) R_{E}$, and measured the solar wind velocity to be $\sim 640 \mathrm{~km} \mathrm{~s}^{-1}$. The calculation of the delay between the observations recorded at the spacecraft and the incidence of these conditions at the subsolar magnetopause was determined using the technique described by Khan and Cowley (1999). In this instance, since the spacecraft was located relatively close to the Earth-Sun line, the $X_{G S M}$ position of the spacecraft and the observed solar wind speed have been used to calculate the transit time of field changes between the spacecraft and the subsolar bow 
shock. Thereafter, the technique employs a fourfold decrease in the solar wind speed at the shock, and a subsequent deceleration through the magnetosheath to an inflow speed of $\sim 20 \mathrm{~km} \mathrm{~s}^{-1}$ at the subsolar magnetopause. This procedure gives an average delay of $\sim 42 \mathrm{~min}$ for the propagation of information from the spacecraft to the magnetopause, and has been included here in our analysis.

The magnetic field components of the IMF $\left(B_{x}, B_{y}\right.$ and $B_{z}$ ), time-shifted by $42 \mathrm{~min}$, are shown in Fig. 2 for the interval 06:30-07:30 UT. The IMF conditions are fairly stable throughout the interval of major interest, i.e. 06:4507:20 UT, with the majority of the field strength arising from the $B_{x}$ and $B_{y}$ components. There is a decrease of about $5 \mathrm{nT}$ in both of these components prior to this interval at 06:42 UT, although the field strength did not vary a great deal overall. IMF $B_{y}$ remained strongly positive (duskward) throughout, varying between 5 and $10 \mathrm{nT}$. In contrast the IMF $B_{z}$ was virtually zero, with small positive (northward) values until $\sim 07: 15$ UT, whereafter it turned to small negative values. The solar wind density and velocity were slightly higher than typical values, $\sim 6 \mathrm{~cm}^{-3}$ and $\sim 640 \mathrm{~km} \mathrm{~s}^{-1}$, respectively, resulting in a dynamic pressure of $\sim 5-6 \mathrm{nPa}$ during this interval.

\subsection{MSP observations}

The red line $(630.0 \mathrm{~nm})$ and green line $(557.7 \mathrm{~nm})$ emissions measured by the Ny Ålesund MSP from 06:45-07:20 UT are shown in the upper and lower panels, respectively, of Fig. 3. The plot is colour-coded in intensity, with the data plotted as a function of time and zenith angle from 0 to $-80^{\circ}$ (the southern half of the scan range). The approximate position of the ESR is given by the horizontal black dotted line using the corresponding emission altitudes mentioned earlier for each wavelength.

Five poleward moving auroral forms (PMAFs) were identified in both wavelengths with the highest luminosity observations recorded in the red line emissions (top panel). Each enhancement of the red line emission began between $-45^{\circ}$ and $-60^{\circ}$ zenith angle, with the onset time marked by a vertical black line when the red line luminosity exceeded $5 \mathrm{kR}$. Assuming that the red line emission peaks at $250 \mathrm{~km}$, then the PMAFs can be interpreted as originating equatorward of the location of the ESR field-aligned beam. The PMAFs then expanded to smaller zenith angles, indicative of their poleward migration, with some passing through the ESR beam. This poleward motion of red line transients is an accepted signature of pulsed reconnection during either southward IMF conditions or, as is the case here, strong IMF $B_{y}$ conditions (e.g. Sandholt et al., 1990, 1998; Rodger et al., 1995; Yeoman et al., 1997) and are the auroral counterpart of dispersed ion precipitation observations made by low-latitude satellites (Sandholt and Newell, 1992). The onset of each event identified from the red line emissions was 06:49 UT, 06:52 UT, 06:56 UT, 07:04 UT and 07:12 UT (numbered 1-5 in Fig. 3).

The black solid line in the upper panel of Fig. 3 marks the equatorward edge of the $5 \mathrm{kR}$ contour in the red line emis-

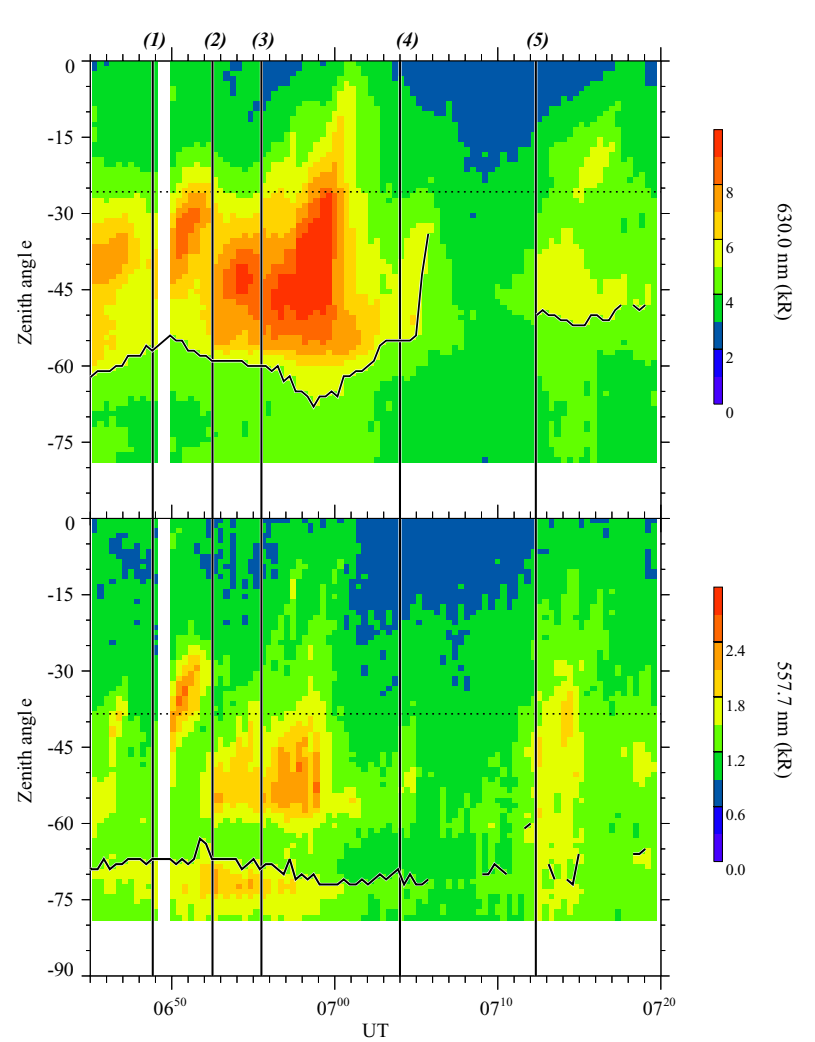

Fig. 3. The top and bottom panels show the $630.0 \mathrm{~nm}$ (red line) and $557.7 \mathrm{~nm}$ (green line) optical emissions, respectively, from the $\mathrm{Ny}$ Ålesund MSP as a function of zenith angle (negative to the south) and UT, between 06:45 and 07:20 UT on 4 December 1999, colourcoded in intensity. The approximate zenith angle position of the ESR is shown by the dotted horizontal line in both panels, derived assuming a peak emission altitude of $250 \mathrm{~km}$ for the $630.0 \mathrm{~nm}$ emissions and $150 \mathrm{~km}$ for the $557.7 \mathrm{~nm}$ emissions. The onset of six intense features identified from the $630.0 \mathrm{~nm}$ optical signatures are marked by solid vertical lines, numbered 1 to 5 , with the dot-dashed line, indicating a key time in the ESR data (see Fig. 7). On the upper panel, the latitudinal variation of the $5 \mathrm{kR}$ contour has been shown to highlight the equatorward edge of the intense emission region. Superposed on the lower panel is the latitudinal variation of the poleward edge of the lower band of high intensity $557.7 \mathrm{~nm}$ emissions, which has been assumed to be associated with precipitation originating from the closed field line region.

sion. This equatorward edge of the intense red line auroral emissions $(630.0 \mathrm{~nm})$ has been used by previous authors (e.g. Moen et al., 2001) as a proxy for the location of the open closed field line boundary (OCFLB). The red line emission associated with the PMAFs is excited by electrons of magnetosheath origin, following reconnection at the dayside magnetopause and can be considered to be located on the first newly-open field lines at the onset of reconnection. However, there will exist a latitudinal displacement between the ionospheric footprint of the OCFLB and the appearance of these bright $630.0 \mathrm{~nm}$ emissions, with the latter observed at higher latitudes. There is a travel-time of $\sim 3 \mathrm{~min}$ between the onset of reconnection at the magnetopause and the appearance of 
the most energetic cusp particles in the ionosphere, by which time the newly-opened flux tubes will have convected poleward slightly (Lockwood and Smith, 1992). For cusp particles precipitating along magnetic field lines convecting polewards at several hundred $\mathrm{m} \mathrm{s}^{-1}$, a travel time of $3 \mathrm{~min}$ will produce an offset of $\sim 0.5^{\circ}$ between the actual position of the OCFLB and the appearance of the bright aurora. In principle, the electrons ought to arrive into the ionosphere sooner than the ions, however, in order to retain charge neutrality in the plasma, the electrons travel with the ions, arriving at the same time into the ionosphere.

Rodger and Pinnock (1997) have suggested that if reconnection were occurring at the magnetopause, as magnetosheath particles gain entry to the magnetosphere along newly-opened field lines, previously trapped magnetospheric particles should escape into the solar wind. Near-Earth satellites have detected the outflow of magnetospheric particles during reconnection events (Scholer et al., 1982), while the inflow of magnetosheath particles clearly associated with cusp precipitation occurs poleward of any gap created by the loss of this emission (Lockwood, 1997). The typical energies of such trapped magnetospheric particles lost to the magnetosheath at the onset of reconnection are a few $\mathrm{keV}$, producing a loss of intense emissions in the $557.7 \mathrm{~nm}$ waveband (green line emissions). Any luminosity increase equatorward of this "dark region" would be associated with magnetospheric plasma sheet particles, with the poleward edge of the region marking the OCFLB in the ionosphere. Such a "dark region" is indeed seen in the $557.7 \mathrm{~nm}$ observations (bottom panel in Fig. 3), especially between 06:45 UT and 07:05 UT. A black line marked on the lower plot of Fig. 3 indicates the poleward border of the green line emission associated with the plasmasheet particle population. This auroral gap has recently been reported by Sandholt et al. (2001) to coincide with the precipitation regime termed "void" in the statistical studies of Newell and Meng $(1992,1994)$, who categorised different regions of the high-latitude ionosphere by the precipitation levels observed using low-orbiting satellite data. The green line luminosity increases poleward of the "dark region", in association with the PMAFs highlighted in the red line observations. After 07:05 UT, the green line intensity dropped to $<1.5 \mathrm{kR}$, making it increasingly difficult to separate the observations into two distinct bands. A comparison of the two boundaries marked on the red and green line emissions will be discussed in detail later in the discussion.

The strongest optical feature in both wavelengths began at $\sim 06: 57$ UT (event 3 ), with the high intensity luminosity feature intensifying at the equatorward edge before moving poleward, reaching the location of the ESR a few minutes thereafter. At the same time as the poleward motion of the red line emission, there was an equatorward motion of the equatorward boundary, which is a classic characteristic of the auroral dynamics in the convection throat region (Sandholt and Farrugia, 1999). The intense precipitation ends abruptly just after 07:00 UT, although there appears to be a remnant "tail" branching off near 07:04 UT. This latter intensification

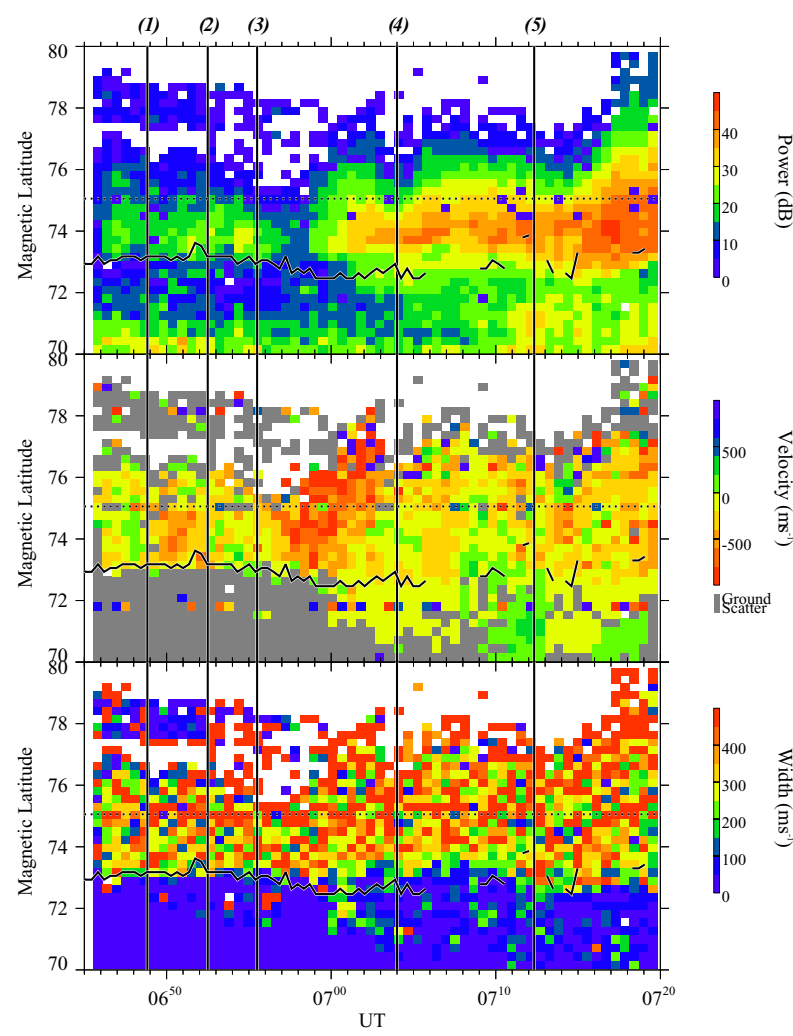

Fig. 4. The backscatter power (top panel), line-of-sight velocity (middle panel) and spectral width (bottom panel) measurements along beam 9 of the CUTLASS Finland radar for the time interval 06:45-07:20 UT, between 70-80 ${ }^{\circ}$ magnetic latitude. The Doppler velocities are shown with negative (positive) values representing flow away from (towards) the radar, and grey regions indicating identified as ground scatter. Also shown on each of the panels is the poleward boundary of the lower band of enhanced emission recorded in the $557.7 \mathrm{~nm}$ wavelength by the MSP, as described in Fig. 3, projected to an assumed emission altitude of $150 \mathrm{~km}$. The five vertical lines mark the onset times of the intense luminosity increases in the red line emissions noted from the MSP data. The horizontal dotted line represents the magnetic latitude of the ESR.

has been marked as a separate feature (event 4), although it is unclear if it is related to the prior event.

\subsection{CUTLASS Finland radar observations}

Data from beam 9 of the CUTLASS Finland radar are presented in Fig. 4 with the three panels showing backscatter power, line-of-sight (1-o-s) velocity and spectral width from top to bottom in the interval 06:45-07:20 UT. Positive (negative) velocities are associated with flow towards (away from) the radar. Areas colour-coded grey indicate those returns identified as ground scatter, characterised by low 1-o-s velocity (less than $\sim 50 \mathrm{~m} \mathrm{~s}^{-1}$ ) and narrow spectral width (less than $\left.\sim 50 \mathrm{~m} \mathrm{~s}^{-1}\right)$. The horizontal dotted line represents the magnetic latitude of the ESR $\left(\sim 75^{\circ}\right)$. The vertical lines indicate the onset times of the auroral intensities as timed from the red line emissions in Fig. 3. Also, superposed on the 
radar observations is the latitudinal variation of the poleward edge of the lower band of green line emission, converted into magnetic coordinates, assuming an altitude of peak emission of $150 \mathrm{~km}$, which represents the OCFLB.

Several different signatures of pulsed reconnection in HF radar data have been reported; transient changes in the convective flow pulsed ionospheric flows, PIFs (Provan et al., 1998) or poleward moving enhancements in the backscatter power, poleward moving radar auroral forms, PMRAFs (e.g. Wild et al., 2001). PMRAFs can occur in conjunction with PIFs, although they can also be associated with steady convective flow. Davies et al. (2002) have commented on the various nomenclatures used to describe the ionospheric counterpart of dayside transients. An increase in the backscatter power was observed at $\sim 06: 47 \mathrm{UT}$, associated with a change in the line-of-sight velocity from low speeds towards the radar, to corresponding speeds away from the radar. This re-orientation of the flow signifies a restructuring of the flow pattern. The increase in power occurred a few minutes after the near $5 \mathrm{nT}$ change in IMF $B_{y}$ observed by ACE at $\sim 06: 45$ UT. At $\sim 06: 50$ UT, just after the onset of event 1 , the backscatter power increased by $\sim 20 \mathrm{~dB}$, in association with an increase in flow away from the radar to $>500 \mathrm{~m} \mathrm{~s}^{-1}$. The high velocity and power feature then moved poleward from $\sim 73^{\circ}$ to $\sim 75^{\circ}$. The subsequent poleward motion in backscatter power is characteristic of a PMRAF, while the additional enhancement and motion in the 1-o-s velocities suggests that a PIF was also observed at this time. The power increased again a minute or so following the onset of event 2, although no flow counterpart was observed at this time. The enhanced power also only lasted a few minutes before returning to quiet conditions $(\sim 10 \mathrm{~dB})$.

Event 3 ( $\sim 06: 56$ UT) was associated with the strongest response in the radar data, as well as in the optical data, with both the power and velocity showing significant enhancements, although not simultaneously. The flow increase was much more pronounced than that in event 1 , with velocities peaking $>800 \mathrm{~ms}^{-1}$ away from the radar, together with a clear $\sim 5^{\circ}$ poleward propagation of the region of enhanced plasma velocity over the following $\sim 6 \mathrm{~min}$ into the polar cap. The power reduced before an enhancement occurred a few minutes after both the onset time of the luminosity increase observed by the MSP and the increase in the velocity data. A poleward motion in the backscatter power began at $\sim 06: 59$ UT. Also associated with event 3 was a slight equatorward motion of the equatorward edge of the high spectral width regions, from $\sim 73^{\circ}$ to $\sim 71^{\circ}$, with a similar, though less pronounced, motion mapped by the latitudinal variation of the low latitude $557.7 \mathrm{~nm}$ emissions.

Since both the boundary of high/low spectral widths and the poleward edge of the low latitude $557.7 \mathrm{~nm}$ emissions are approximately collocated, the suggestion that the former may be taken as a proxy for the OCFLB could be correct. However, it should be noted that in the observations presented here, much of the low spectral width region has been identified as ground scatter. In general, cusp backscatter is usually characterised by high power and high spectral width (Baker et al., 1995; Rodger et al., 1995) and can be seen here as the region poleward of the suggested location of the OCFLB (black line). Backscatter associated with the low-latitude boundary layer (LLBL) tends to be of lower return power than the cusp region, making the LLBL very difficult to identify. In the example discussed here, it is indeed difficult to identify the LLBL because it appears overlaid by a region of ground scatter, a fact that often happens with the radar data (Milan and Lester, 2001). We also note that after 07:00 UT, the scatter in the region equatorward of the OCFLB is identified as low velocity ionospheric scatter with generally low spectral width. Furthermore, the general level of backscatter power also became enhanced after this time. The change could be associated with a change in the propagation mode. Nevertheless, we feel confident in suggesting that since the two boundaries we have highlighted here, i.e. the boundary marked by the green line emission and the boundary between high/low spectral width, lie very close to each other, at least in this instance the latter can indeed be used as a proxy for the OCFLB. Thus, the equatorward motion of the high spectral width boundary $\left(\sim 1-2^{\circ}\right)$ can be interpreted as a burst of reconnection appending an amount of newly-opened flux to a localised region of the polar cap, causing the boundary to move equatorward slightly, in accordance with the pulsed reconnection model of Cowley and Lockwood (1992). This equatorward motion only lasted for a few minutes, after which time the newly-opened flux was incorporated into the polar cap, resulting in the boundary returning close to its original position. However, the line tracking the poleward edge of the low latitude $557.7 \mathrm{~nm}$ emissions remained equatorward of the high spectral width region for the remainder of the interval. The details of event 3 are discussed in depth later.

The radar enhancements associated with event 3 continued until 07:03 UT, after which time the velocities began to return to background levels, and the equatorward boundary of the high spectral width region returned to more poleward latitudes. Event 4 was marked as a remnant of event 3 in the optical data, as it appeared to be related to the intense luminosity increases observed during the prior event. In the radar data there appeared to be only slight variations associated with this increase in luminosity. The onset of event 4 appeared to trigger a small poleward motion in the backscatter power, starting at $\sim 74^{\circ}$ and extending to $\sim 76^{\circ}$ over the following $\sim 8 \mathrm{~min}$. There also appears to be an immediate equatorward expansion of the high backscatter power region, as you would expect in response to a burst of reconnection. However, no increase in 1-o-s velocity or significant changes in spectral width were observed.

As the backscatter power enhancement of event 4 moved poleward, at $\sim 07: 09$ UT, a further intensification in the power was noted just equatorward of this region, indicating the onset of the fifth event. Power levels at this slightly lower latitude increased to $\sim 40 \mathrm{~dB}$, together with a slight equatorward motion of the high spectral width region also at $\sim 07: 09$ UT. The backscatter power observations clearly indicated a step in the intensity of the radar aurora, as the peak in- 


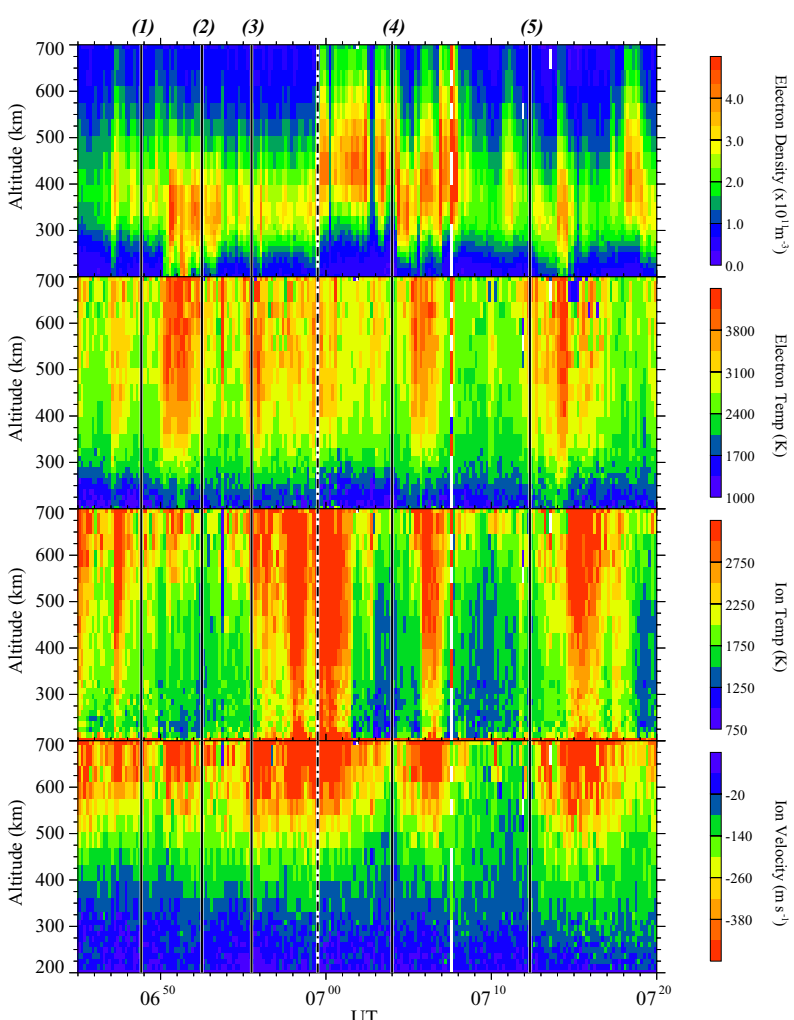

Fig. 5. Field-aligned observations from the ESR located at $\sim 75^{\circ}$ magnetic latitude, between 06:45 UT and 07:20 UT. From top to bottom, the four panels show electron density $\left(N_{e}\right)$, electron temperature $\left(T_{e}\right)$, field parallel ion temperature $\left(T_{i}\right)$ and ion velocity $\left(V_{i}\right)$, presented as a function of height and analysed at 10-s resolution. The velocities are colour-coded in a similar fashion to the Doppler velocities shown in the middle panel of Fig. 4. Again, the vertical lines indicate the onset times of cusp-like precipitation identified from the MSP data, numbered accordingly. The dot-dashed line at $\sim 06: 59$ UT indicates a time where the ESR made observations of particular interest (see comments in the text.)

tensification associated with event 4 moved poleward. There was also evidence of some poleward moving structure in the velocity data at $\sim 07: 12 \mathrm{UT}$. The backscatter power remained continuously elevated for much of the interval thereafter.

\subsection{ESR observations}

The four panels in Fig. 5 show the data obtained from the field-aligned long pulse observations by the ESR radar between 06:45-07:20 UT. From top to bottom, the plot shows electron density $\left(N_{e}\right)$, electron temperature $\left(T_{e}\right)$, fieldaligned ion temperature $\left(T_{i}\right)$ and field-aligned ion velocity $\left(V_{i}\right)$. The last of these parameters is plotted using the same colour scheme as the CUTLASS velocity observations, with positive (negative) velocities indicating downward (upward) flow. The data have been analysed at 10-s resolution and are presented as a function of altitude and time. The black numbered solid lines again indicate the onset times of the PMAFs from the MSP, shown in Fig. 3. The dot-dashed line highlights the time at which a significant change in the ionospheric structure occurred and altered the electron density. Details of this will be discussed later.

It is immediately obvious from these data that a great deal of structure is present in the ionosphere during the interval. In general, if the ESR were observed within the vicinity of strong electron precipitation, then the electron temperature and density measurements would increase accordingly, as has been predicted by Davis and Lockwood (1996). At the onset of event 1, the ESR observed initially low values of electron density and temperature. At $\sim 06: 50 \mathrm{UT}$, the electron temperature increased at altitudes above $300 \mathrm{~km}$, followed some $30 \mathrm{~s}$ later by an increase in density at all altitudes down to the E-region (not shown here). These increases in electron density and temperature coincided with the peak optical emissions in both the red and green wavelengths of event 1, and also the first PMRAF observed by the Finland radar. No significant increase in ion temperature was observed during event 1 indicating the absence of ion-neutral frictional heating. Such ion heating occurs due to the presence of large electric fields driving high F-region plasma flow (e.g. Davies et al., 1997, 1999a). At higher altitudes $(>500 \mathrm{~km})$ there was an increase in upward fieldaligned flows, which reduced slightly once the electron temperatures returned to pre-event levels. During periods of elevated electron and/or ion temperatures, enhanced pressure gradients will cause the plasma to flow outwards along the field lines at high altitudes. Thus, reducing the temperatures should result in a reduction of the upflow of the plasma. The electron density in the F-region within the ESR beam remained at a higher level than before the event throughout the duration of event 1, although the E-region density did start to decrease towards the end of the event.

After the onset of event 2, at 06:52 UT, the F-region electron density began to decrease, with a marked reduction observed at the time when the electron temperatures dropped to $<3000 \mathrm{~K}$. During event 2 , there was no significant enhancement in electron density at low altitudes $(<300 \mathrm{~km})$, suggesting that any precipitating electrons at this time over the localised region of the ESR were not of sufficient energy to penetrate to E-region altitudes, unlike during event 1. Moreover, no significant ion heating or upward field-aligned ion velocities at altitudes $>500 \mathrm{~km}$ were observed. From the MSP data shown in Fig. 3, it is clear that the PMAF onset and subsequent intensification remained equatorward of the estimated position of the ESR, which would explain why the ESR does not show any evidence of particle precipitation associated with this event.

The electron temperature had increased just before the onset of event 3 , but the major initial change was the enhanced ion temperature at altitudes above $400 \mathrm{~km}$. Correspondingly, no significant changes in electron density occurred following the onset of event 3 . This can be explained by two separate processes: one, the increased recombination resulting from the enhanced ion temperature and the other, the enhanced upward ion flows, which were uniformly upwards for altitudes $>400 \mathrm{~km}$ at this time, with velocity increases of the order of 
$500 \mathrm{~m} \mathrm{~s}^{-1}$ above $600 \mathrm{~km}$. At about 06:57 UT, the ion temperature was again enhanced at all altitudes, followed by a brief reduction at $\sim 06: 59 \mathrm{UT}$, before a further major increase. Coincident with the initial onset of the intense ion heating following event 3, the Finland radar observed the main PMRAF/PIF with an associated burst of flow with a large poleward component of some $800 \mathrm{~m} \mathrm{~s}^{-1}$ or more, which is equivalent to an electric field of $\sim 40-50 \mathrm{mV} \mathrm{m}^{-1}$. The duration of the heating event and strong upflowing ions correspond well with the poleward flow velocities and the increase in power observations by the HF radar.

The ion temperature increase at $\sim 07: 00$ UT coincided with a dramatic jump of the altitude of the F2 peak electron density (indicated by the dot-dashed line). The structure of the ionosphere clearly changed after this increase in altitude, as elevated electron densities were observed at altitudes $>350 \mathrm{~km}$, suggesting that there may be an increase in the level of precipitation into the f-o-v of the ESR. These enhanced densities occurred despite the presence of high ion temperature, which would result in an increase in the recombination rate and field-aligned flows, leading to a suppression of the electron concentration. Although such a reduction in electron concentration was observed at lower altitudes, there must be a source of plasma to explain the increase at higher altitudes. Following the end of the intense heating event ( 07:02 UT), the electron densities began to recover with evidence of the electron densities penetrating to lower F-region altitudes, although the peak density remained above $400 \mathrm{~km}$.

Event 4 was characterised by another short burst of particle precipitation, inferred from the increase in electron temperature with an associated drop in the altitude of the density enhancements. After a few minutes, at $\sim 07: 05 \mathrm{UT}$, the ion temperature also increased, corresponding to another jump in altitude of the peak in electron density. Reduced ion and electron temperatures were observed in the following 5-min interval ( 07:07-07:12 UT), again concurrent with weak fieldaligned flows. The electron density was less structured, albeit still variable, with the peak enhancements returning to lower altitudes.

At $\sim 07: 12$ UT, a final increase in electron temperature was observed in conjunction with upward flowing plasma and evidence of the onset of an increase in ion temperature, coincident with event 5 . The electron density began to increase at this onset with a further enhancement a couple of minutes later at $\sim 07: 14$ UT which was seen to extend over a range of altitudes $(\sim 200-500 \mathrm{~km}$, together with an increase in electron temperature). Ion temperatures remained fairly weak during these enhancements. Thereafter, high ion temperatures were observed, signifying ion-frictional heating, coincident with upward flows and a dramatic reduction in electron concentration. After the intense ion heating event at 07:18 UT, the electron concentration increased over the altitude range $\sim 300-600 \mathrm{~km}$, with the F2 peak occurring at a higher altitude than the previous intensification.

To summarise, during the five luminosity increases identified by the MSP, the ESR data indicate a correspondence with cusp precipitation, inferred from electron density and temperature measurements. On the other hand, the ion heating, which implies large ion velocities or changes in direction of ion flow, was present only on some occasions. Events 1, 4 and 5 show increases in electron concentration and temperature that would be expected in the vicinity of cusp-like precipitation. However, event 3 was complicated by ionfrictional heating, modifying the electron concentration. In the following discussion, we relate the ESR observations to the modelling work of Davis and Lockwood (1996) where appropriate.

\section{Discussion}

The MSP data presented here indicate 5 clear PMAFS which have been related in the past to transient reconnection at the dayside magnetopause. When investigating data collected from the HF radar and ESR, we see some correspondence between the optical auroral enhancements and the radar observations. The increases in velocity observed by the HF radar (Fig. 4, events 3, 5) coincide with enhanced ion temperatures measured by the ESR due to ion-neutral frictional heating. The high-speed flows measured by the HF radar had a component which was directed towards the polar cap, indicating that reconnection had occurred recently. It is interesting to note that the radar intensifications identified as PMRAFs, in general, appeared a minute or so after the optical PMAFs signatures. Indeed, the power enhancements in the HF data seem to appear at the trailing edge of the velocity enhancements, which may be a result of increased backscatter from gradients in electron density, which are likely to be present at the edges of high flow regions in which the electron density becomes suppressed through ion-neutral frictional heating. The optical data clearly shows enhanced luminosity during these events, suggestive of strong precipitation penetrating to both F- and E-region altitudes at the approximate location of the ESR (Fig. 5, event 3), which will account, at least in part, for the structure observed in the electron density measurements.

\subsection{Location of the open-closed field line boundary}

Turning our attention first to the HF radar and optical data, we found a significant correlation between these two data sets when we superposed the location of the equatorward boundary of the "dark" auroral region in the green line emission onto the radar data (Fig. 4). The latitudinal variation of this boundary follows the equatorward edge of the region of scatter identified as ionospheric, which has a high spectral width and generally high backscatter power. Both of these two features in the HF radar data have been suggested to be proxies for the location of the OCFLB, although due to problems with the contamination by ground backscatter, as well as propagation effects, it has never been proven conclusively that the boundary between the high/low spectral width or the equatorward edge of high backscatter power can definitely pinpoint the location of the OCFLB. In this study, the coinci- 
dence of the two boundaries identified using different instruments suggests that both of these techniques can be used to mark the ionospheric footprint of the OCFLB.

Previous studies have also related the equatorward edge of the intense red line optical emissions with the high/low spectral width boundary, and found that these two regions are collocated (Moen et al., 2001). The red line aurora results from magnetosheath particles precipitating into the ionosphere at and following the onset of reconnection, with the resulting ground signature displaced from the OCFLB by the traveltime of the particles into the ionosphere, as the field line moves away from the reconnection site. The region of high spectral width within the cusp region is generally associated with variable electric field behaviour, which may be caused by wave activity in the Pc1/2 frequency band generated in the equatorial plane at the magnetopause (e.g. André et al., 2000). The information resulting in the enhancement is Alfvén travel-time delayed to the ionosphere, which, in general, is $\sim 2 \mathrm{~min}$. Thus, if both these processes are initiated at the onset of reconnection and take similar time scales to travel into the ionosphere, then the boundaries marking these regions may be displaced from the OCFLB by the same amount, suggesting that these boundaries may be collocated.

However, there are several factors that must be carefully considered when trying to relate these two boundaries. Upon studying the optical emissions from the Ny Ålesund MSP, a peak emission altitude of $150 \mathrm{~km}$ for the green line aurora and $250 \mathrm{~km}$ for the red line aurora have been assumed. In Fig. 6 we compare the high/low spectral width boundary with the lower $5 \mathrm{kR}$ contour from the red line emission and the equatorward boundary of the dark region in the green line emission shown in Fig. 3. The upper panel in Fig. 6 shows the spectral width data as a function of time, as previously displayed in the bottom panel of Fig. 4, but now with the ground scatter removed. The solid line overlaid on this plot marks the lower boundary at which the spectral width exceeds $250 \mathrm{~m} \mathrm{~s}^{-1}$ (Baker et al., 1995). In the bottom panel we compare this spectral width boundary (solid line) with the equatorward edge of the dark region in the green line emission (green dotted line), assuming an emission altitude of $150 \mathrm{~km}$ (as marked in the bottom panel of Fig. 3), and the equatorward edge of the $5 \mathrm{kR}$ contour in the red line emission for the two emission altitudes of $200 \mathrm{~km}$ and $250 \mathrm{~km}$. The lower red line shows the $5 \mathrm{kR}$ contour, assuming an emission altitude of $250 \mathrm{~km}$, previously shown in the top panel of Fig. 3, while the upper red line tracks the latitudinal variation of this contour using a lower emission altitude of $200 \mathrm{~km}$.

Concentrating on the green line boundary, we find that the dotted line appears very close to the high/low spectral width boundary between $~ 06: 45 \mathrm{UT}$ and 07:05 UT, as mentioned above. This would seem to support the choice of the higher altitude for the green line emission in this case. The two red lines appear to be close to both of these boundaries, at least for the first $10 \mathrm{~min}$ or so of the interval, while after this it does appear equatorward of the other two lines. This would appear to be in contrast to the finding of Moen et al. (2001), where they showed a high correlation between the location of the
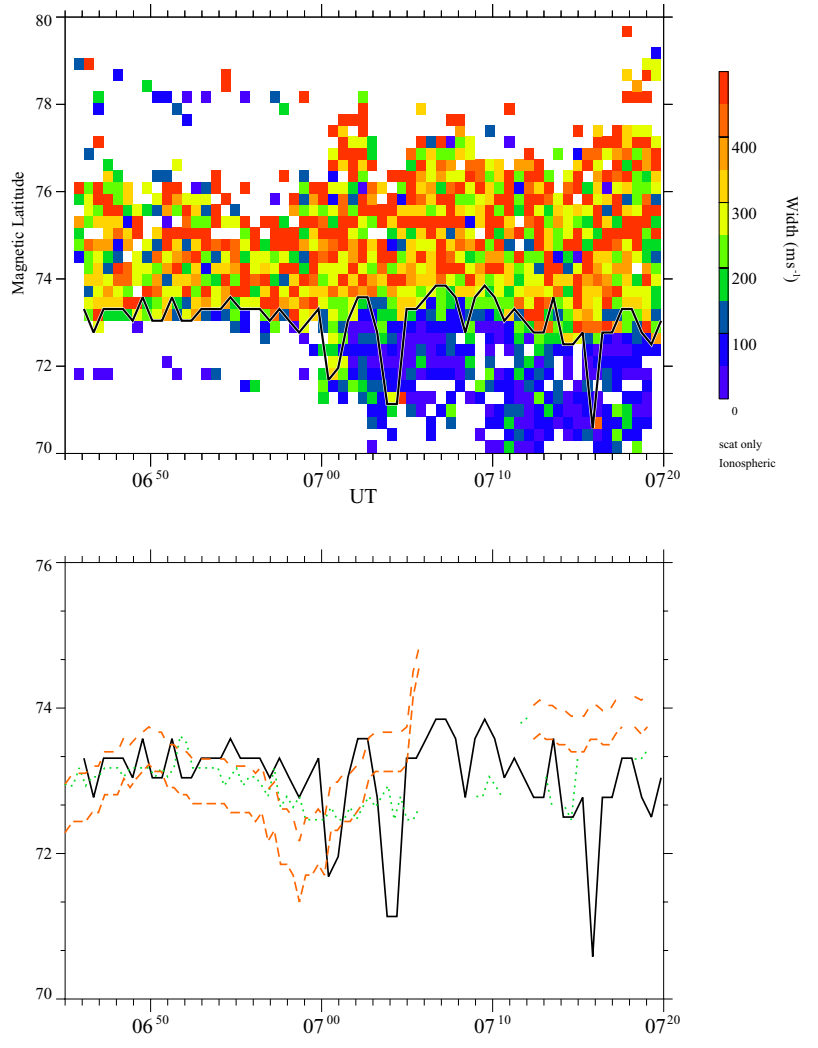

Fig. 6. The upper panel shows the spectral width component measured along beam 9 of the CUTLASS HF radar as a function of UT, colour-coded in velocity between $0-500 \mathrm{~m} \mathrm{~s}^{-1}$, with the ground scatter removed. The solid black line marks the southernmost latitude of spectral widths $>250 \mathrm{~m} \mathrm{~s}^{-1}$. The lower panel then compares this boundary (solid black line) with the poleward edge of the lower band of $557.7 \mathrm{~nm}$ emissions (green dotted line), as previously shown in Figs. 3-4, assuming an emission altitude of $150 \mathrm{~km}$. Also shown here is the latitudinal variation of the equatorward edge of the $5 \mathrm{kR}$ contour in the $630.0 \mathrm{~nm}$ emissions plotted as a function of local time, assuming a range of emission altitudes between $200 \mathrm{~km}$ and $250 \mathrm{~km}$, marked by the upper and lower red lines, respectively.

high/low spectral width boundary and the equatorward edge of intense luminosity in the red line emission, assuming an emission altitude between $215 \mathrm{~km}$ and $250 \mathrm{~km}$. The emission altitude for the red line emission can peak anywhere between 200-500 km, and in our prior discussions we have assumed a value of $250 \mathrm{~km}$. Here we have shown that a poleward shift in latitude of up to $\sim 1^{\circ}$ can be expected if the emission altitude is reduced from $250 \mathrm{~km}$ to $200 \mathrm{~km}$. Moen et al. (2001) used an emission altitude of $215 \mathrm{~km}$ for one of their events, where justification came from the physics of their observations. By using an emission altitude closer to $200 \mathrm{~km}$ (upper red line), we find that the $630.0 \mathrm{~nm} 5 \mathrm{kR}$ contour is close to, or just poleward of, both the high/low spectral width boundary and the green line deduced OCFLB. Although the choice of the $5 \mathrm{kR}$ contour is relatively arbitrary, it separates well the time varying red line emission associated with pulsed reconnection from the relatively steady emission equatorward of this 


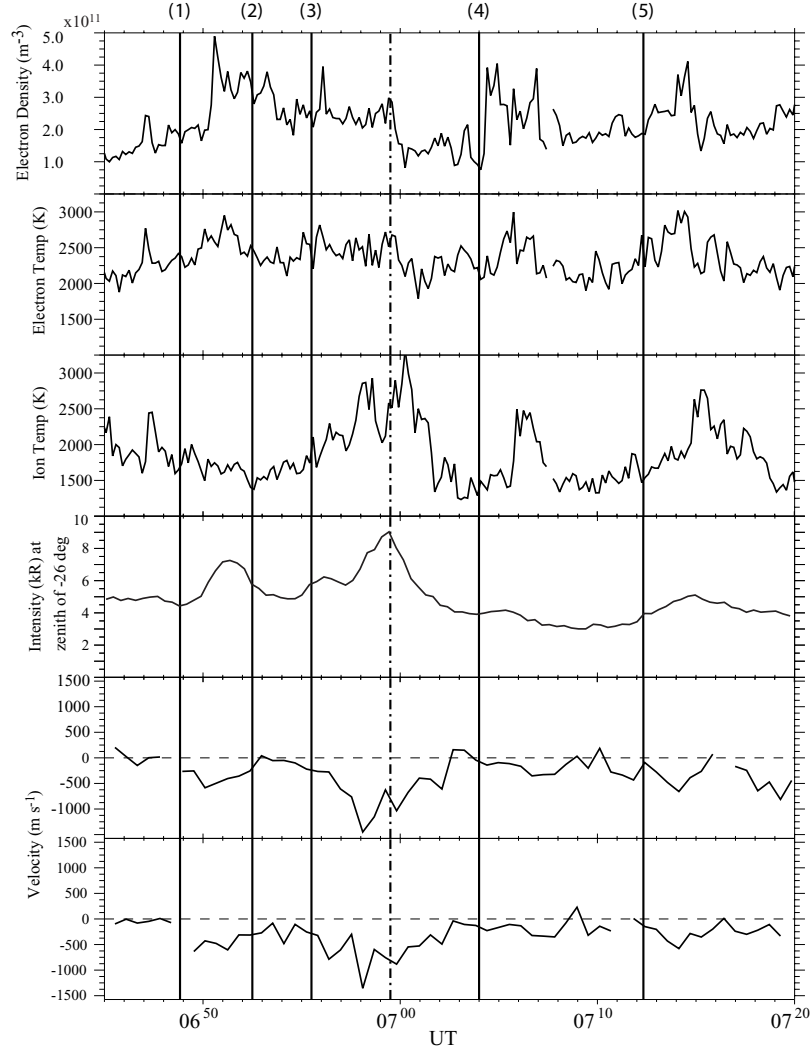

Fig. 7. The top three panels show the electron density, electron temperature and ion temperature observed by the ESR at an F-region altitude of $\sim 300 \mathrm{~km}$, for the time interval 06:45-07:20 UT. Optical emission intensities in the $630.0 \mathrm{~nm}$ wavelength band (red line) at the approximate zenith angle position of the ESR for an assumed altitude of emission of $250 \mathrm{~km}$, recorded by the MSP, are presented in the fourth panel. The bottom two panels show line-of-sight velocity measurements from beam 9 and range gate 39 and 40, respectively, which points approximately over the ESR. The solid vertical lines mark the five cusp events. The dot-dashed line highlights a change in the ESR measurements and coincides with the peak in the optical red line emissions overhead at the ESR.

(Fig. 3). As a result, it is clear that one must be very careful when relating optical, in particular the red line emission, and radar features. By using both instruments together, we have been able to better estimate the location of the OCFLB, and have found that similar results can be obtained from each technique.

\subsection{Comparison of ESR observations with predicted signa-} tures in the cusp region

Davis and Lockwood (1996), hereafter referred to at DAL96, predicted signatures in electron temperature and density during precipitation events for different positions of the ESR relative to the location of the cusp, by considering the output parameters of an auroral precipitation model which was used successfully to model the spatial and temporal distribution of $630.0 \mathrm{~nm}$ emissions in response to pulsed reconnection.
This model reproduced the pulsed signatures associated with a varying reconnection rate during episodic merging, though the effects of either uniform or varying plasma flow were not taken into account.

Figure 7 presents a time series of selected data from each of the instruments, over the time interval of interest, with particular care taken to present data taken from a common location. The top three panels show the electron density, electron temperature and ion temperatures as observed by the ESR at an altitude of $\sim 300 \mathrm{~km}$. The fourth panel presents the red line emissions from the MSP at the latitude of ESR, computed for a peak in emission of $250 \mathrm{~km}$ altitude. Finally the bottom two panels show Doppler 1-o-s velocities from the CUTLASS Finland radar from range gates 39 and 40 of beam 9 , respectively, which are the approximate gates located over the position of the ESR. Efforts have been made to select colocated observations, allowing for direct comparison of all three instruments. The solid vertical lines indicate the times of the PMAFs.

Panel 4 of Fig. 7 shows that the red line emissions did not increase at the location of the ESR until a minute or so after event 1 , at which time simultaneous increases in electron density and, to a weaker extent, in electron temperature were observed. The general morphology of the measured electron temperature and density enhancements for event 1 were very similar to those predicted by DAL96 for the ESR positioned near the poleward edge of the precipitation region. While the electron density remained elevated for a few minutes, the electron temperature rapidly decreased with the cessation in precipitation, as was predicted in the modelling analysis of DAL96. The density enhancement then finally returned to background levels a short time after the luminosity had also decayed.

However, the predictions proposed by the modelling analysis of DAL96 were based on the assumption that no electric fields were present and thus, did not take into account the plasma flow in the ionosphere. Convection in the highlatitude ionosphere will change the ionospheric concentration, as discussed earlier, and has an impact on the observations within the ionospheric footprint of the cusp region. For event 1, no evidence of ion frictional heating is present, which would suggest that strong flows caused by enhanced electric fields were not present (Fig. 7). This suggests that the modelling analysis could represent, at least to a first approximation, a realistic explanation for the observations. On the other hand, the l-o-s velocity measured by the CUTLASS HF radar (bottom panel), observed an increase in poleward velocities to $600 \mathrm{~m} \mathrm{~s}^{-1}$ at the onset time of the luminosity increase, suggesting that a change in flow followed the precipitation. It should be noted that the volume of a CUTLASS range-beam cell is an order of magnitude larger than that of the ESR. Thus the observations by the HF radar indicate an average over the range cell, and hence, an increase in velocity in this region will not necessarily correspond to an increase in a localised region, such as in the ESR beam.

Continuing the comparison of the observations and the modelling analysis, events 4 and 5 also displayed signatures 
predicted by DAL96, although these were modified by intense ion heating in the latter part of each interval. Initially, the luminosity in the $630.0 \mathrm{~nm}$ wavelength was associated with increases in both electron density and temperature. As with the previous event, the MSP observed the initial brightening of the optical aurora equatorward of the location of the ESR in both of these cases, with the intensification then moving poleward. For event 4, the peak in the luminosity occurred at the time of the increase in electron density and temperature, exhibiting typical signatures of pulsed reconnection as proposed by DAL96. However, in the following minutes, an increase in the plasma flow in the vicinity of the ESR resulted in an increase in ion temperature, which, in turn, depleted the electron density. The introduction of large-scale flows altered the ionospheric structure such that the modelling analysis of DAL96 became inapplicable. Similarly, during event 5 , the optical signature and the electron density and temperature peaked at 07:14 UT, at which time the ion temperature increased significantly, resulting in a reduction in the electron density. Here the plasma flow was observed at the onset of the optical brightening, with the intense ion heating taking place a few minutes later. This delay is probably due to the different spatial sizes of the CUTLASS and ESR observation areas.

The red line intensification marked as event 2 did not appear to produce any significant change in the auroral luminosity over the ESR beam (Fig. 7, panel 4). It should be noted that the onset times marked here have been timed from the appearance of the optical aurora, as shown in Fig. 3, which, in general intensified equatorward of the position of the ESR. During event 2, the subsequent poleward motion of the intensification carried the auroral signature towards the location of the ESR (dotted line in Fig. 3), passing overhead just prior to the onset time of event 3 ( $\sim 06: 55$ UT). In Fig. 7, a small increase in the luminosity of the red line emissions overhead of the ESR occurred just before the onset of event 3, with the resulting peak in luminosity occurring a minute or so after. We associate this smaller peak with the poleward motion of the auroral brightening of event 2 . Also at $\sim 06: 55 \mathrm{UT}$, the electron temperature increased in conjunction with the luminosity increase, and to a lesser degree an increase in the electron density was observed. The electron density remained at this level for the remainder of the interval and continued into event 3 .

At the onset of the third event, the l-o-s flow observed by CUTLASS increased to a poleward velocity of close to $1.5 \mathrm{~km} \mathrm{~s}^{-1}$. The increase in the 1-o-s velocity observed by the HF radar has been identified as a PIF in Fig. 4, and has been associated with pulsed reconnection. However, the ESR observations during event 3 cannot be compared directly to the modelling work of DAL96 due to the large electric fields modifying the ionospheric conditions, inferred from the ion heating event and the increase in flow observed by the HF radar. Apart from a short-lived spike in the electron density, neither the electron density nor the temperature illustrate any significant change for about $3 \mathrm{~min}$ after the onset of event 3 . The electron densities were slightly higher at the start of the interval, $\sim 2.5 \times 10^{-11} \mathrm{~m}^{-3}$ compared with $1.0 \times 10^{-11} \mathrm{~m}^{-3}$ later in the event. Just before 07:00 UT (dot-dashed line), a rapid decrease in electron density was followed by a decrease in electron temperature, which was the result of the rapid increase in the altitude of the peak electron density. This sharp jump in altitude of the electron density occurred at precisely the time of the peak in the intensity of the red line luminosity observations ( $\sim 06: 59$ UT) above the ESR and just after the start of the second increase in ion temperature (dot-dashed line). Figures 3 and 4 clearly show that both optical and HF radar aurora during event 3 brightened equatorward of the ESR, and then moved poleward. Thereafter, the optical emissions decayed away, in conjunction with the decrease in poleward plasma flow but with heightened ion temperature for a short time (Fig. 7). The ion temperature decreased rapidly thereafter $(\sim 07: 02 \mathrm{UT})$, while the electron density peak remained at higher latitudes.

If no ionospheric heating had been observed during event 3 , then the change in altitude of the peak electron density enhancements at $\sim 06: 59$ UT could be attributed to a change in the energy of the precipitating electrons. No spacecraft data were available during this event to determine the particle energies precipitating into the ionosphere. Clearly the presence of the strong plasma flows modified the ionosphere and most probably contributed to the processes resulting in the change in altitude of the F2 peak in the electron density. The modelling analysis of DAL96 cannot be compared directly to the observations during this event due to the strong plasma flows. Nevertheless, the increase in electron density at higher altitudes suggests the onset of the precipitation over the location of the ESR and combined with the increase in ion heating depleting the electron concentration at lower altitudes, could result in the step in the altitude of the peak electron density.

\subsection{Motion of the patch of enhanced velocity}

Figure 8 shows four spatial maps of colour-coded l-o-s velocities measured by the CUTLASS Finland radar in magnetic latitude/magnetic local time coordinates from the interval 06:51-07:05 UT, where the ionospheric flow pattern associated with event 3 can be better observed. Overlaid on the velocity measurements are plasma flow vectors derived using the beam-swinging technique, where the plasma flow remains the same across the radar f-o-v for a given L-shell (Villain et al., 1987; Ruohoniemi et al., 1989). The velocity vectors have been binned into $2^{\circ}$ bands of magnetic latitude between 64 and $80^{\circ}$. Located in the centre of each plot is Svalbard, where the ESR (large solid dot) and Ny Ålesund MSP are located. Also shown on these plots is a statistical location of the auroral oval for $K_{p}=4$, which was the value of the geomagnetic index between 06:00 and 09:00 UT. The large solid black arrows show the general direction of the plasma flow in the scan. The collection of small black dots located at $\sim 10: 00$ MLT and near the poleward edge of the statistical oval represent our estimated position of the OCFLB during the interval 06:45-07:20 UT, as determined from the poleward edge of the "dark" auroral band in the 
(a)

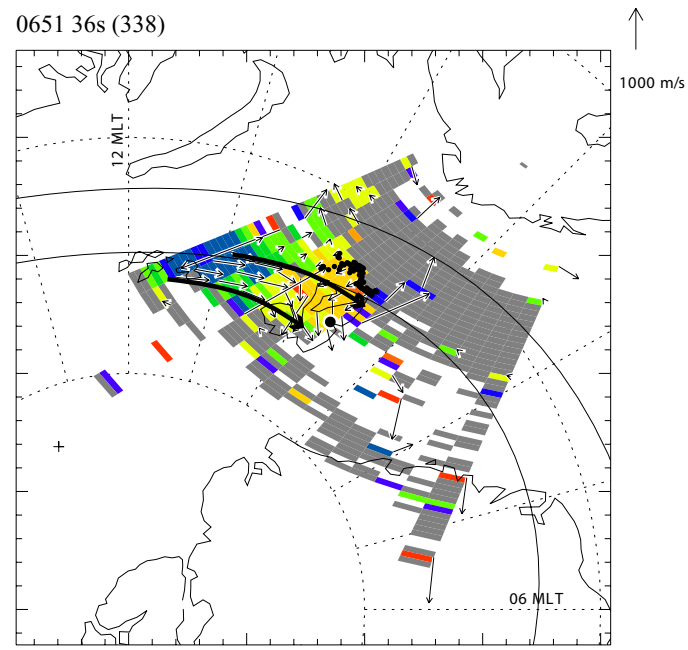

(c)

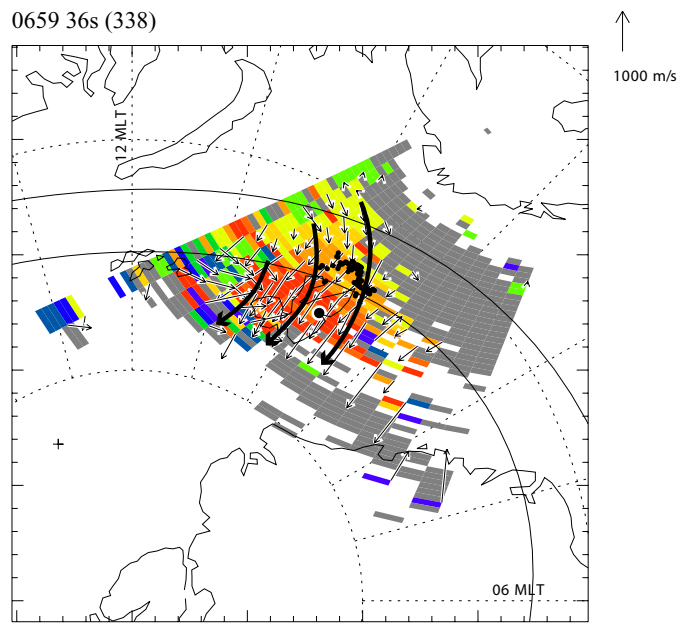

(b)
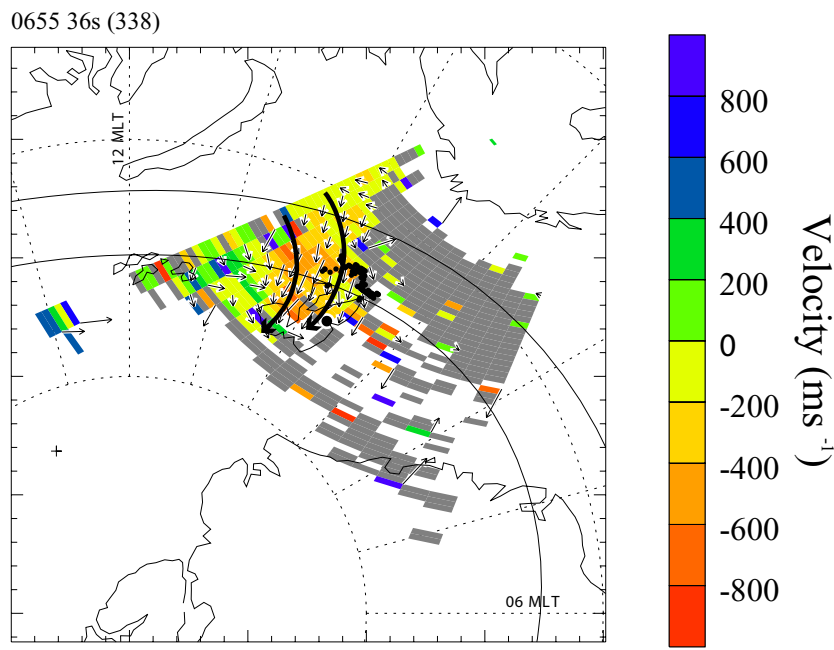

Ground Scatter

(d)

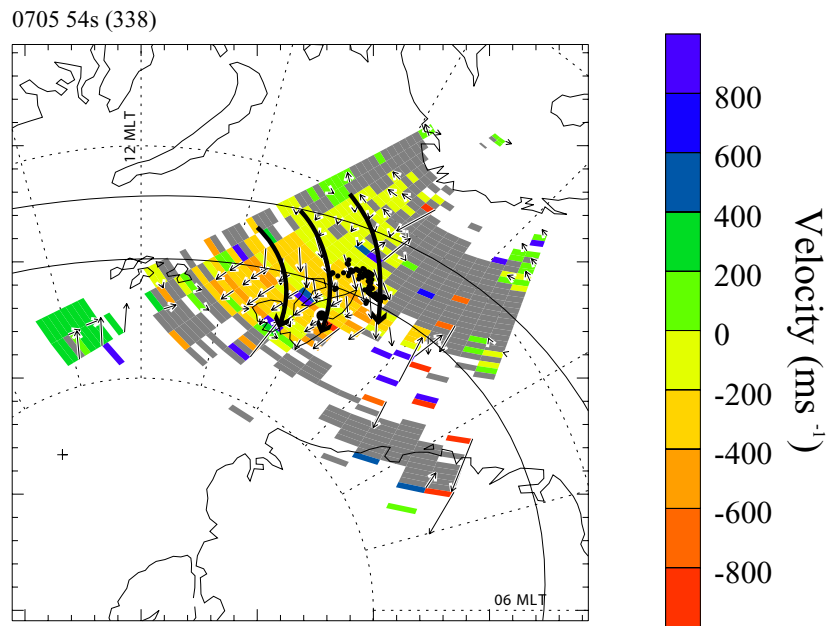

Ground

Scatter

Fig. 8. Spatial maps of line-of-sight velocity measured by the CUTLASS Finland radar between 06:51 UT and 07:05 UT, colour-coded with negative (positive) velocities, indicating flow away from (towards) the radar. Each scan is superposed on a grid of magnetic latitude and MLT, shown by the dashed part-circles and lines. Also included is a statistical auroral oval for $K_{p}=4$. The small arrows represent convection velocity vectors derived using the beam-swinging technique of Ruohoniemi and Baker (1989); the large arrows simply highlight the direction of the overall flow over the location of the ESR, shown as a large solid dot. The collection of smaller dots $\sim 10$ MLT and $\sim 73^{\circ}$ magnetic latitude show the position of the open/closed field line boundary taken from the MSP data.

green line optical emissions (Fig. 3), as a function of MLT. It is encouraging to see that these points lie very close to the poleward edge of the statistical oval and also in the region of intensifying flows as one progresses through the scans.

In the first plot (scan a), illustrating the flow pattern prior to the auroral intensification, the majority of the flow was in a westward azimuthal direction, in accordance with a dawn convection flow cell distorted by strong positive (duskward)
IMF $B_{y}$. Much of the backscatter was concentrated in the eastern beams at this time, which is most probably related to the propagation conditions of the radar signal and a more structured ionosphere from which to receive a backscatter signal. Nevertheless, poleward flows of $\sim 200-400 \mathrm{~m} \mathrm{~s}^{-1}$ were observed just poleward of the inferred OCFLB. By 06:55 UT (scan b), the flow vectors appeared to rotate to more poleward directions at higher latitudes while still main- 
taining a significant azimuthal component at lower latitudes. The data are suggestive of a drifting of the plasma from the east into the radar f-o-v, which subsequently moved into the polar cap region. The following scan confirms this (scan c), with a clear rotation in the flow vectors observed between lower and higher latitudes. Notice also that the enhancement extended azimuthally by $\sim 06: 59 \mathrm{UT}$, covering the entire radar f-o-v at high latitudes, encompassing the Svalbard archipelago. This signified the maximum intensification of the event with the strongest of the poleward flow vectors $\left(\sim 1000 \mathrm{~m} \mathrm{~s}^{-1}\right)$ passing over the island, and poleward of the OCFLB. The beam-swung vectors clearly illustrate the flow pattern, which continued into the next scan at $\sim 07: 01 \mathrm{UT}$ (not shown). The westward extension of the plasma flow began to retract at this point, while the high latitude poleward motion continued for a time. Overall, the magnitude of the flow decreased thereafter, and by $\sim 07: 05$ UT (scan d), the flow velocities returned to values similar to those prior to the enhancement, with the flow direction also in a similar orientation.

The observations can be compared with theoretical models of convection driven by transient dayside reconnection, as discussed by Cowley and Lockwood (1992), and more recently adapted by Milan et al. (2000) and McWilliams et al. (2001). In these latter studies the authors made direct observations in the post-noon sector and concluded that they were consistent with an azimuthally propagating reconnection site extending in the post-noon sector, which excited the large-scale flows previously predicted (Cowley and Lockwood, 1992; Lockwood et al., 1993b; Cowley, 1996). McWilliams et al. (2001) further hypothesised that since observations were made in the post-noon sector for both orientations of IMF $B_{y}$, a corresponding signature ought to be present in the pre-noon sector. Here we present a response in the plasma flow in the pre-noon sector, influenced by strong positive IMF $B_{y}$ conditions. Figure 8 clearly illustrates the expansion of flow from the east propagating westward through the $\mathrm{f}-\mathrm{O}-\mathrm{V}$ of the radar before the poleward motion into the polar cap was visible. The location of the OCFLB is consistent with the hypothesis that the strongest flow velocities are observed poleward of this boundary; however, we do not directly observe the motion of the reconnection site, as was previously observed by McWilliams et al. (2001) in the post-noon sector. We observe the response in the flow following a reconnection event, in the fashion predicted by Cowley and Lockwood (1992). A schematic illustrating a possible scenario of the flow reconfiguration is shown in Fig. 9, which has been adapted from Fig. 9c of Cowley and Lockwood (1992) for positive IMF $B_{y}$. The grid is shown in magnetic local time and latitude. The collection of small dots near 10:00 MLT and $\sim 73^{\circ}$ magnetic latitude indicates the estimated position of the OCFLB during the interval studied, from the MSP green line observations (Fig. 3), while the curved arrowed lines show the direction of the large-scale flow associated with the appearance of the newly-opened flux.

From this schematic, at the onset of a pulse of reconnec-

\section{$\mathrm{By}>\mathbf{0}$}

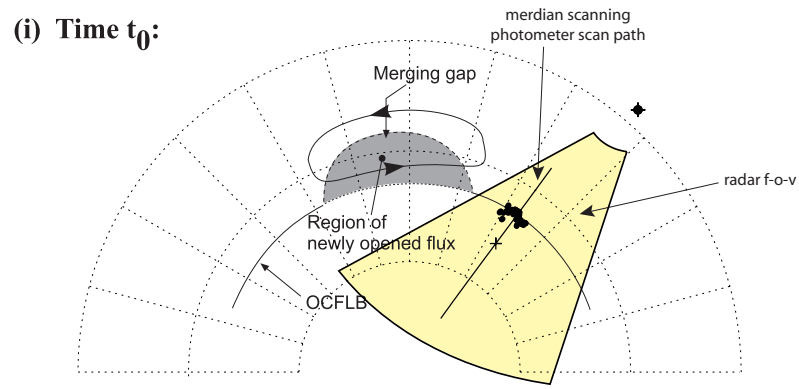

(ii) Time $\mathbf{t}_{\mathbf{0}}+\mathbf{d t}$ :

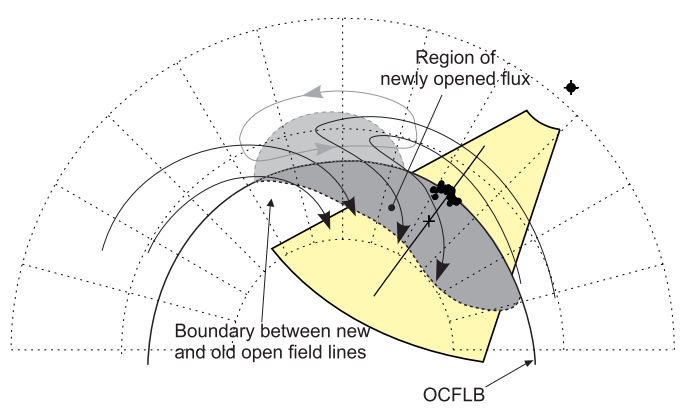

Fig. 9. A diagram showing the appearance and subsequent evolution of a patch of newly-opened flux under the influence of positive IMF $B_{y}$ conditions. This schematic has been adapted from Fig. 9c previously shown in Cowley and Lockwood (1992). The solid semicircle represents the open/closed field line boundary, which has been positioned over our estimated boundary location (small dots $\sim 10 \mathrm{MLT}$ and $73^{\circ}$ ). The f-o-v of the radar at 07:00 UT is shown by the yellow shaded area with the location and the meridian scan of the MSP shown by the cross and line in the middle of the radar f-o-v. The grey shaded area represents the newly-open flux appended to the dayside boundary. The curved arrows indicate the convection streamlines. The initial response of reconnection under positive IMF $B_{y}$ (a) evolves into (b) after a short time. The flow is initially localised within the region of the newly-opened flux appended to the open/closed field line boundary (OCFLB). Thereafter, the tension force imposed by IMF $B_{y}$ pulls the flow westward producing an azimuthal flow at lower latitudes before turning poleward at higher latitudes into the polar cap. The OCFLB moves equatorward and the region of newly-opened flux extends longitudinally (adapted from Cowley and Lockwood, 1992).

tion, the IMF $B_{y}$ tension force produces an azimuthal flow in the vicinity of the newly-opened flux. This appears in the radar f-o-v from the east and propagates westward. The observations show this eastern flow enhancement near the OCFLB location (scan a), with the general pattern suggesting a predominantly east-west flow. As time progresses (bottom schematic), the region of open flux is pulled azimuthally under the influence of the IMF $B_{y}$ tension force and the boundary between new and old open flux moves poleward and ex- 
tends longitudinally (dotted line). The observations confirm this azimuthal extension prior to the poleward propagation at higher latitudes. The solid curved lines indicate the direction of the flow in response to the IMF $B_{y}$ tension force, and we see that there is a definite rotation towards the dawn sector as the flows are directed into the polar regions. In Fig. 8, the centre of the enhanced region of flow was tracked and found to initially move in a predominantly azimuthal direction, with the flow rotating to a more poleward direction a few minutes into the intensification. The azimuthal component of this motion was calculated to be similar to the plasma convection velocity of $\sim 1 \mathrm{~km} \mathrm{~s}^{-1}$ and, therefore, it was likely that reconnection had ceased at this time. The scenario envisaged by McWilliams et al. (2001) of the "peeling" effect of the reconnection region was not directly observed here, as we did not see the effect of the reconnection X-line extend into the pre-noon sector flow observations. Instead, we observed the response in the flow to a pulse of reconnection occurring outside the f-o-v of the radar. We infer that reconnection has occurred prior to the appearance of the intense velocity feature which moves azimuthally under the strong IMF $B_{y}$ and then poleward as the newly-opened flux is incorporated into the polar cap, poleward of the OCFLB. We note, however, that the optical observations suggest that the merging line must map to a local time close to the meridian observed by the MSP, since the loss of green line emission equatorward of the cusp aurora suggests a loss of magnetospheric plasma to the solar wind. It is not possible to resolve these two apparently conflicting observations without extended spatial coverage of the flows and the aurora.

\section{Summary}

In this paper we have presented multi-instrument observations, using the MSP at Ny Ålesund, the ESR and the Finland HF radar, to probe and understand the dynamics of the cusp region during pulsed reconnection events. Several combinations of the three remote-sensing techniques have previously been utilised to gain an insight into the turbulent cusp region; however, very few studies have been conducted using these three instruments simultaneously. The unique nature of this study arises from the co-location of the meridian scanning photometer and the ESR, both of which are ideally located within the Finland radar f-o-v. The ESR made field-aligned measurements of the ionospheric plasma parameters, while the meridian scanning photometer showed evidence of cusplike precipitation. Detailed analysis of the data has allowed us to arrive at several conclusions:

1. The ionospheric projection of the merging line is identified from the loss of precipitation in the green line aurora just equatorward of the cusp aurora. This loss of emission occurs due to the escape of magnetospheric plasma to the magnetosheath along newly-opened field lines.
2. Since the speed of the plasma convection across this boundary is directly related to the magnetopause reconnection rate, the radar event during 06:55-07:05 UT is a classic example of the convection response to a pulse of enhanced magnetopause reconnection rate.

3. The close association between the radar signature and auroral boundary (the equatorward boundary intensifications followed by the poleward moving auroral forms, PMAFs) confirms the previous interpretation that PMAFs are signatures of transient reconnection. The high spectral width region follows both the equatorward boundary of the intense red line emissions and the poleward edge of the loss of the green line emission, suggesting each boundary can be used as a proxy for the OCFLB.

4. The time delay of the radar response with respect to the auroral brightening is likely to be due to the spatial structures forming the auroral forms. Electron density gradients will result in backscatter enhancements originating from the edges of the velocity structures and precipitation regions, thus offsetting the radar observations both temporally and spatially.

5. The ESR observations have been compared to the modelling analysis of DAL96. Where the conditions are appropriate, i.e. no strong plasma flow or associated ionneutral frictional heating, the observations followed the prediction of the modelling work. From this analysis we were able ascertain that the ESR was observing near the poleward edge of the precipitating region. However, the limitations of the model were apparent in particular cases where the large plasma flows were measured by the ESR and HF radar, such as in event 3.

6. The HF data during event 3 was shown to conform to the convection models of Cowley and Lockwood (1992), illustrating the plasma reconfiguration in response to a burst of reconnection influenced primarily by strong positive IMF $B_{y}$. The beamswung vectors in Fig. 8 illustrate the initial east-west orientation of the flow before increasing in magnitude and turning to more poleward directions.

7. We note that the flow observations are not entirely consistent with the auroral observations in terms of the extent of the ionospheric footprint of the reconnection site. The flow observations imply that this does not extend into the CUTLASS f-o-v, while the auroral observations imply that the reconnection site is identified by the MSP (see point 1 above).

Acknowledgements. The CUTLASS HF radars were deployed and operated by the University of Leicester, and are supported by the UK Particle Physics and Astronomy Research Council (PPARC grant PPA/R/R/1997/00256), the Finnish Meteorological Institute, and the Swedish Institute of Space Physics. The authors would like to thank the Director of EISCAT and his staff for operating 
the facility and providing the EISCAT radar data. EISCAT is an international association supported by the research councils of Finland (SA), France (CNRS), Germany (MPG), Japan (NIPR), Norway (NAVF), Sweden (NFA), and the United Kingdom (PPARC). We also thank the principal investigators, N. Ness and D. L. McComas for supplying the ACE Science Center with high time resolution data from the ACE MAG and SWEPAM instruments, respectively. The auroral observation program on Svalbard is supported by the Norwegian Research Council and the Norwegian Polar Institute. Drs H. Khan, J .A. Davies and S. E. Milan are supported on PPARC grant PPA/G/O/1999/00181.

The Editor in Chief thanks E. Lund and another referee for their help in evaluating this paper.

\section{References}

André, R., Pinnock, M., and Rodger,A.S.: Identification of the low-altitude cusp by Super Dual Auroral Radar Network radars: A physical explanation for the empirically derived signature, J. Geophys. Res., 105, 27 081-27 094, 2000.

Baker, K. B., Dudeney, J.R., Greenwald, R. A., Pinnock, M., Newel, P.T., Rodger, A.S., Mattin, N., and Meng, C.-I.: HF radar signatures of the cusp and the low-latitude boundary layer, J. Geophys. Res., 100, 7671-7695, 1995.

Cowley, S. W. H.: Magnetospheric asymmetries associated with the $Y$-component of the IMF, Planet. Space Sci., 29, 79-96, 1981.

Cowley, S. W.H., Freeman, M., Lockwood, M., and Smith, M. F.: The ionospheric signatures of flux transfer events, in Proc. Of the Int. Workshop on Cluster: Dayside Polar Cusp, Eur. Space Agency Spec. Publ., ESA SP 300, 105-112, 1991.

Cowley, S. W. H. and Lockwood, M.: Excitation and decay of solar wind-driven flows in the magnetosphere-ionosphere system, Ann. Geophysicae, 10, 103-115, 1992.

Cowley, S.W.H.: The aurora ionosphere and its coupling to the magnetosphere and the solar wind, in: Modern Ionospheric Science, (Eds) Kohl, H., Rüster, R., and Schlegl, K., EGS Publ., Katlenburg-Lindau, pp. 32-66, 1996.

Davies, J. A., Lester, M., and McCrea, I.: A statistical study of ion frictional heating observed by EISCAT, Ann. Geophysicae, 15, 1399-1411, 1997.

Davies, J. A., Lester, M., and McCrea, I.: Solar and seasonal dependence of ion frictional heating, Ann. Geophysicae, 17, 682-691, 1999a.

Davies, J. A., Lester, M., Milan, S. E., and Yeoman, T. K.: A comparison of velocity measurements from the CUTLASS Finalnd radar and the EISCAT UHF system, Ann. Geophysicae, 17, 892902, 1999b.

Davies, J. A., Yeoman, T. K., Lester, M., and Milan, S. E.: A comparison of F-region ion velcouty observations from the EISCAT Svalbard and VHF radars with irregularity drift velocity measurements from the CUTLASS Finland HF radar, Ann. Geophysicae, 18, 589-594, 2000.

Davies, J. A., Yeoman, T.K., Rae, I.J., Milan, S.E., Lester, M., Lockwood, M., and McWilliams, K. A.: Ground-based observations of the auroral zone and polar cap ionospheric responses to dayside transient reconnection, Ann. Geophysicae, 20, 781-794, 2002

Davis, C. J. and Lockwood, M.: Predicted signatures of pulsed reconnection in ESR data, Ann. Geophysicae, 14, 1246-1256, 1996.

Dungey, J. W.: Interplanetary field and the auroral zone, Phys. Res. Lett., 6, 47-48, 1961.
Elphic, R. C., Lockwood, M., Cowley, S. W. H., and Sandholt, P. E.: Flux transfer events at the magnetopause and in ionosphere, Geophys. Res. Lett., 17, 2241-2244, 1990

Goertz, C. K., Nielsen, E., Korth, A., Glassmeier, K.-H., Haldoupis, C., Hoeg, P., and Hayward, D.: Observations of a possible signature of flux transfer events, J. Geophys. Res., 90, 4069-4078, 1985.

Greenwald, R. A., Baker,K. B., Dudeney, J. R., Pinnock, M., Jones, T. B., Thomas, E.C., Villain, J.-P., Cerisier, J.-C., Senior, C., Hanuise, C., Hunsucker, R. D., Sofko, G., Koehler, J., Nielsen, E., Pellinen, R., Walker, A. D. M., Sato, N., and Yamagishi, H.: DARN/SuperDARN: A global view of the dynamics of highlatitude convection, Space Sci. Rev., 71, 761-796, 1995.

Haerendel, G., Paschmann, G., Sckopke, N., Rosenbauer, H., and Hedgecock, P.C.: The frontside boundary layer of the magnetopause and the problem with reconnection, J. Geophys. Res., 83, 3195-3216, 1978

Heppner, J. P.: Polar cap electric field distributions related to the interplanetary magnetic field direction, J. Geophys. Res., 27, 4877, 1972.

Khan, H. and Cowley, S. W. H.: Observations of the response time of high-latitude ionospheric convection to variations in the interplanetary magnetic field using EISCAT and IMP-8 data, Ann. Geophysicae, 17, 1306-1335, 1999.

Lockwood, M., Sandholt, P.E., Cowley, S.W.H., and Oguti, T.: Interplanetary field control of dayside auroral activity and the transfer of momentum across the dayside magnetopause, Planet. Space Sci., 37, 1347-1365, 1989.

Lockwood, M. and Smith, M. F.: The variation of reconnection rate at the dayside magnetopause and cusp ion precipitation, J. Geophys. Res., 97, 14 841-14 847, 1992.

Lockwood, M., Carlson Jr., H. C., and Sandholt, P. E.: Implications of the altitude of transient $630.0 \mathrm{~nm}$ dayside auroral emissions, $\mathrm{J}$. Geophys. Res., 98, 15 571-15 587, 1993a.

Lockwood, M., Moen, J., Cowley, S.W.H., Farmer, A. D., Løvhaug, U.P., Lühr, H., and Davda, V. N.: Variability of dayside convection and motions of the cusp/cleft aurora, Geophys. Res. Lett., 20, 1011-1014, 1993b.

Lockwood, M., Cowley, S. W.H., and Smith, M. F.: Comment on " $B y$ fluctuations in the magnetosheath and azimuthal flow velocity transients in the dayside ionosphere" by Newell and Sibeck, Geophys. Res. Lett., 21, 1819-1822, 1994.

Lockwood, M.: Relationship of the dayside auroral precipitations to the open-closed separatix and the pattern of convective flow, J. Geophys. Res., 102, 17 475-17487, 1997.

Lockwood, M., McCrea, I. W., Milan, S. E., Moen, J., Cerisier, J. C., and Thorolfsson, A.: Plasma structure within poleward-moving cusp/cleft auroral transients: EISCAT Svalbard radar observations and an explanation in terms of large local time extent of events, Ann. Geophysicae, 18, 1027-1042, 2000.

McComas, D. J., Bame, S. J., Barker, P., Feldman, W. C., Phillips, J.L., Riley, P., and Griffee, J.W.: Solar Wind Electron Proton Alpha Monitor (SWEPAM) for the Advanced Composition Explorer, Space Sci. Rev., 86, 561-612, 1998.

McWilliams, K.A., Milan, S.E., Yeoman, T.K., Sigwarth, J. B., Frank, L. A., and Brittnacher, M.: IMF $B_{y}$ dependence of the relative position of the dayside ultraviolet auroral oval and the HF radar cusp, J. Geophys. Res., 106, 29 027-29 036, 2001.

Milan, S. E., Yeoman, T. K., Lester, M., Thomas, E. C., and Jones, T. B.: Initial backscatter occurrence statistics from the CUTLASS HF radars, Ann. Geophysicae, 15, 703-718, 1997.

Milan, S. E., Lester, M., Cowley, S. W. H., Moen, J., Sandholt, P. E., 
and Owen, C. J.: Meridian- scanning photometer, coherent HF radar and magnetometer observations of the cusp: a case study, Ann. Geophysicae, 17, 159-172, 1999.

Milan, S.E., Lester, M., Cowley, S.W.H., and Brittnacher, M.: Convection and auroral response to a southward turning of the IMF: Polar UVI, CUTLASS and IMAGE signatures of transient magnetic flux transfer at the magnetopause, J. Geophys. Res., 105, 15 741-15 756, 2000.

Milan, S. E. and Lester, M.: Interhemispheric differences in the HF radar signatures of the cusp region: A review through the study of a case example, Adv. Polar. Upper Atmos. Res., 15, 159, 2001.

Moen, J., Sandholt, P.E., Lockwood, M., Denig, W., Løvhaug, U.P., Lybekk, B., Egeland, A., Opsvik, D., and FriisChristensen, E.: Events of enhanced convection and related auroral activity, J. Geophys. Res., 100, 23 917-23 934, 1998.

Moen, J., Carlson, H. C., Milan, S. E., Shumilov, N., Lybekk, B., Sandholt, P. E., and Lester, M.: On the collocation between dayside auroral activity and coherent HF radar backscatter, Ann. Geophysicae, 18, 1531-1549, 2001.

Neudegg, D., Yeoman, T.K., Cowley, S.W.H., Provan, G., Haerendel, G., Baumjohann, W., Auster, U., Fornaçon, K.-H., Georgescu, E., and Owen, C.J.: A flux transfer event observed at the magnetopause by the Equator-S spacecraft and in the ionosphere by the CUTLASS HF radar, Ann. Geophysicae, 17, 707711, 1999.

Neudegg, D., Cowley, S. W. H., Milan, S. E., Yeoman, T. K., Lester, M., Provan, G., Haerendel, G., Baumjohann, W., Nikutowski, B., Büchner, J., Auster, U., Fornaçon, K.-H., and Georgescu, E.: A survey of magnetopause FTEs and associated flow bursts in the polar ionosphere, Ann. Geophysicae, 18, 416-435, 2000.

Newell, P. T. and Meng, C.-I.: Mapping of the dayside ionosphere to the magnetopause according to particle precipitation events, Geophys. Res. Lett., 19, 609-612, 1992.

Newell, P. T. and Sibeck, D. G.: Upper limits on the contribution of FTEs to ionospheric convection, Geophys. Res. Lett., 20, 28292832, 1993.

Newell, P. T. and Meng, C.-I.: Ionospheric projection of magnetospheric regions under low and high solar wind pressure conditions, J. Geophys. Res., 99, 273-286, 1994.

Pinnock, M., Rodger, A.S., Dudeney, J.R., Rich, F., and Baker, K. B.: High spatial and temporal resolution observations of the ionospheric cusp, Ann. Geophysicae, 13, 919-925, 1995.

Provan, G., Yeoman, T.K., and Milan, S.E.: CUTLASS Finland radar observations of the ionospheric signatures of flux transfer events and the resulting plasma flows, Ann. Geophysicae, 16, 1411-1422, 1998.

Reiff, P.H., and Burch, J.L.: IMF $B_{y}$-dependent plasma flow and Birkeland currents in the dayside magnetosphere. 2. A global model for northward and southward IMF, J. Geophys. Res., 90, 1595-1609, 1985.

Reiff, P. H., Spiro, R. W., and Hill, T. W.: Dependence of polar cap potential drop on interplanetary parameters, J. Geophys. Res., 86, 7639-7648, 1981.

Rodger, A. S., Mende, S. B., Rosenberg, T. J., and Baker, K. B.: Simultaneous optical and HF radar observations of the ionospheric cusp, Geophys. Res. Lett., 15, 2045-2048, 1995.

Rodger, A.S. and Pinnock, M.: The ionospheric response to flux transfer events: the first few minutes, Ann. Geophysicae, 15, 685-691, 1997.

Ruohoniemi, J. M. and Baker, K. B.: Large-scale imaging of highlatitude convection with Super Dual Auroral Radar Network HF radar observations, J. Geophys. Res., 103, 20 797-20 811, 1998.
Ruohoniemi, J. M., Greenwald, R. A., Baker, K. B., Villian, J.-P., Hanuise, C., and Kelley, J. D.: Mapping high-latitude plasma convection with coherent HF radars, J. Geophys. Res., 94, 13 463-13 477, 1989.

Russell, C. T. and Elphic, R. C.: Initial ISEE magnetometer results: magnetopause observations, Space Sci. Rev., 22, 681-715, 1978.

Russell, C. T. and Elphic, R. C.: ISEE observations of Flux Transfer Events at the dayside magnetopause, Geophys. Res. Lett., 6, 3336, 1979.

Sandholt, P. E., Lockwood, M., Oguti, T., Cowley, S. W. H., Lybekk, B., Egeland, A., and Willis, D. M.: Midday auroral breakup events and related energy and momentum transfer from the magnetosheath, J. Geophys. Res., 95, 1039-1060, 1990.

Sandholt, P.E. and Newell, P. T.: Ground and satellite observations of an auroral event cusp/cleft equatorward boundary, J. Geophys. Res., 97, 8685-8691, 1992.

Sandholt, P.E., Farrugia, C. J., Moen, J., and Cowley, S.W.H.: Dayside auroral configurations: Response to southward and northward rotations of the interplanetary magnetic field, J. Geophys. Res., 103, 20 279-20 295, 1998.

Sandholt, P.E. and Farrugia, C. J.: On the dynamic cusp aurora and IMF $B_{y}$, J. Geophys. Res., 104, 12 461-12 472, 1999.

Sandholt, P. E., Denig, W. F., Farrugia, C. J., Lybekk, B., and Trondsen, E.: Auroral structure at the cusp equatorward boundary: Relationship with the electron edge of low-latitude boundary layer precipitation, J. Geophys. Res., in press, 2001.

Scholer, M., Hovestadt, D., Ipavich, F. M., and Gloeckler, G.: Energetic protons, alpha particles, and electrons in magnetic flux transfer events, J. Geophys. Res., 87, 2169-2175, 1982.

Smith, C. W., Acuña, M.H., Burlaga, L.F., L'Heureux, J., Ness, N.F., and Scheifele, J.: The ACE Magnetic Fields Experiment, Space Science Reviews, 86, 611-632, 1998.

Stone, E.C., Frandsen, A.M., Mewaldt, R. A., Christian, E. R., Marglies, D., Ormes, J.F., and Snow, F.: The Advanced Composition Explorer, Space Sci. Rev., 86, 1, 1998.

van Eyken, A. P., Rishbeth, H., and Saunders, M. A.: Initial observations of plasma convection at invariant latitudes of $70-77^{\circ}$, J. Atmos. Terr. Phys., 46, 635-641, 1984.

Villain, J.P., Greenwald, R.A., Baker, K.B., and Ruohoniemi, J. M.: HF radar observations of E-region plasma irregularities produced by oblique electron streaming, J. Geophys. Res., 92, 12 327-12 342, 1987.

Wannberg, G., Wolf, I., Vanhainen, L.-G., Koskenniemi, K., Röttger, J., Postila, M., Markkanen, J., Jacobsen, R., Stenberg, A., Larsen, R., Eliassen, S., Heck, S., and Huuskonen, A.: The EISCAT Svalbard radar: A case study in modern incoherent scatter radar system design, Radio Sci., 32, 2283-2307, 1997.

Weimer, D. R.: Models of the high-latitude electric potentials derived with a least error fit of spherical harmonic coefficients, J. Geophys. Res., 100, 19595-19607, 1995.

Wild, J. A., Cowley, S. W. H., Davies, J. A., Khan, H., Lester, M., Milan, S. E., Provan, G., Yeoman, T. K., Balogh, A., Dunlop, M., Fornaçon, K.-H., and Georgescu, E.: First simultaneous observations of flux transfer events at the high-latitude magnetopause by the Cluster spacecraft and pulsed radar signatures in the conjugate ionosphere by the CUTLASS and EISCAT radars, Ann. Geophysicae, 19, 1491-1508, 2001.

Yeoman, T. K., Lester, M., Cowley, S. W. H., Milan, S.E , Moen, J., and Sandholt, P.E.: Simultaneous observations of the cusp in optical, DMSP and HF radar data, Geophys. Res. Lett., 24, 2251-2254, 1997. 